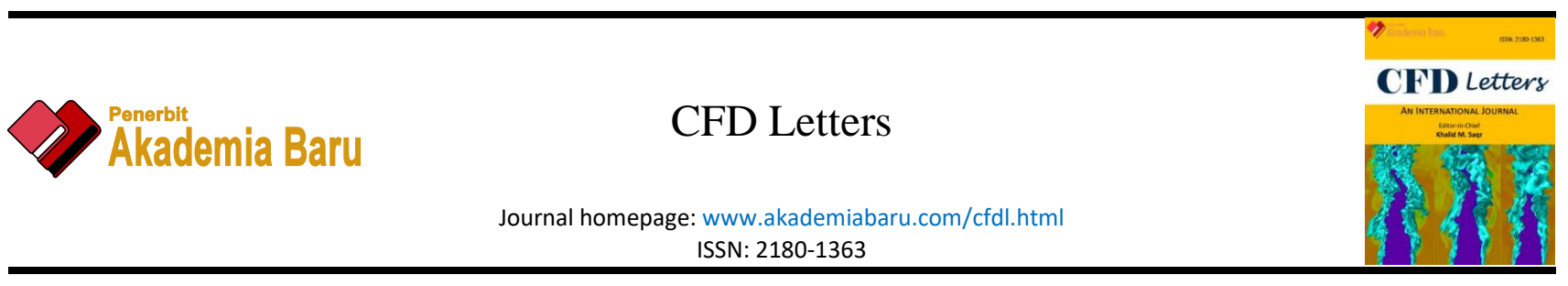

\title{
Fluid-Structure Interaction on The Design of Fully Assembled Shell Eco-Marathon (SEM) Prototype Car
}

\author{
Hedy Soon Keey Tiew ${ }^{1}$, Ming Wei Lee ${ }^{1}$, Chang Wei Shyang ${ }^{1,{ }^{*}}$, Mohammad Hafifi Hafiz Ishak ${ }^{1}$, \\ Farzad Ismail ${ }^{1}$
}

1 School of Aerospace Engineering, Universiti Sains Malaysia, Engineering Campus, 14300 Nibong Tebal, Pulau Pinang, Malaysia

\begin{tabular}{l} 
ARTICLE INFO ABSTRACT \\
\hline
\end{tabular}

\section{Article history:}

Received 23 October 2020

Received in revised form 24 December 2020

Accepted 21 December 2020

Available online 31 December 2020

\begin{abstract}
To achieve high fuel efficiency, vehicles designs are inclined to choose lightweight materials and structures. However, these structures are generally weak, and structural integrity is a common concern. The purpose of this paper is to carry out fluid-structure interaction (FSI) study in one-way coupling analysis on a Shell Eco Marathon (SEM) prototype car which travels in a low-speed range to analyse its structural response. A new set of economical materials is proposed and analysed with the concern on selffabrication process. The Flax fibre composite is introduced as a part of the proposed material set due to its environmental and economic advantages. The study herein is purely a numerical simulation work as a first approach to design a sustainable SEM prototype car. The fully assembled SEM prototype car was analysed with the proposed materials with ANSYS Workbench in the coupling of the fluid (ANSYS Fluent) and structural solver (ANSYS Mechanical) in a one-way FSI. Even with a thin shell design, the proposed material only experiences minimum deformations. The simulations also reveal that the maximum von-Mises stress experienced, after considered the safety factor, is still several order lower than the yield strength. This study has confirmed that the car design has fulfilled its structural requirements to operate at the design speed.
\end{abstract}

Keywords:

One-way FSI analysis; Flax-fibre

composite; Structural analysis

Copyright $\odot 2020$ PENERBIT AKADEMIA BARU - All rights reserved

\section{Introduction}

In Shell Eco-Marathon (SEM), lightweight is one of the crucial design criteria for the competing cars to improve their fuel efficiency and performance. The task of reducing the weight of vehicle structures can be accomplished through material selections. As an effort to promote sustainability, eco-materials are advocated in the material selection via sustainable assessment method since the automotive industry is facing an uptick in the waste and recycling of end-of-life vehicles [1]. The common materials used in past SEM competitions include Glass Fibre-Reinforced Polymer (GFRP), Carbon Fibre-Reinforced Polymer (CFRP) and polycarbonate [2-6]. These materials are generally expensive due to their good material properties. Aligned with the Sustainable Development Goals

\footnotetext{
* Corresponding author.

E-mail address: changweishyang@usm.my (Chang Wei Shyang)
} 
(SDG) set by the United Nations, an economical and sustainable material set is selected and used in this study to provide an alternate option for SEM without compromising safety.

A vehicle which is designed to be light weight generally consists of weak structures. Studying the impact of airflow over the exterior body of the light-weight vehicle is crucial as the weak structures might deform under the effect of aerodynamic forces. As such, incorporating fluid-structure interaction (FSI) analysis is important in evaluating the structural integrity of the fully assembled vehicles in moving motion.

\subsection{SEM Car Material Research}

To have a comprehensive start on the materials of the prototype car, the designs of past SEM teams from different regions were gathered and analysed. Most of the teams conducted researches privately and their findings were not published, thus, the literature is limited. Pertaining to the materials used in the past SEM prototype cars [2-6], the most common material used for shell, chassis and window is Glass Fibre-Reinforced Polymer (GFRP), Carbon Fibre-Reinforced Polymer (CFRP) and polycarbonate, respectively. Polycarbonate is also one of the suggested materials by Shell Global Company [7].

The material selection for the prototype car is based on the following factors in consideration: weight (density), strength (ability to withstand the stresses without yielding), cost, and ease of fabrication. In the new set of materials, the proposed materials are bio-fibre composite, aluminium alloy and acrylic for shell, chassis, and window, respectively. The use of bio-fibre in composites for engineering applications has gained popularity due to the increasing environmental concern and advocative use of sustainable materials. Bio-fibre is cost-effective, low-dense, biodegradable, nonabrasive, and readily available, as well as its specific mechanical properties are comparable to that of glass fibre. The use of Flax fibre as a reinforcement in composite has gained popularity as it is one of the sustainable materials and the most widely used bio-fibre. It is a cellulose polymer, but its structure is more crystalline, making it stronger and stiffer [8]. Recent study on Flax fibre composite [9] also showed the potential of this environmental-friendly alternative.

Aluminium is presently the most popular space frame material. It is approximately one third of the weight of iron, steel, copper, or brass. By using appropriate alloying and treatment, aluminium alloys are available in a variety of strengths. Aluminium outperforms other materials in terms of strength to weight ratio. This advantage assists in the founding of the modern aerospace industry and aluminium is used widely in various forms of transportations.

Acrylic is a type of plastic that is often compared to polycarbonate as it is similar in appearance. Acrylic plastic is less expensive than glass and polycarbonate. It has a higher light transmittance in all thickness and a glass resistance of seventeen times the impact. Moreover, it has a heat bent, as well as it can be polished smoothly and recyclable. It is also easy-to-cut yet durable against scratches and dents. Although polycarbonate is thirty times stronger than acrylic, it costs about $35 \%$ more than acrylic on average.

\subsection{Fluid-Structure Interaction (FSI)}

Fluid-structure interaction can be defined as the dynamic interaction between the fluid flow over a geometry and a structural response of that geometry. In general, the FSI problems are too complex to be solved analytically, so these problems must be analysed numerically. Ha et al., [10] remarked that the numerical approaches used in FSI can be categorised into two groups which are monolithic approach and partitioned approach. 
ANSYS Inc [11] reported that some cases only require one-way coupling or known as direct coupling. For example, pressure loadings result in a deflection of geometry, which changes the flow field around the geometry, but in practice, the change is small enough to be negligible. Thus, in this case, there is no need for two-way FSI. This method usually involves just the unidirectional fields interaction and is solved directly in a single solution. Similarly, Andersson and Ahl [12] remarked that in many engineering applications, in which very small deformations on the structure were induced by forces from moving fluid, the structural response can be established independently after the characteristics of the fluid motion have been determined. In the extensive review on the literature studies, there are many studies of modelling and simulating the interaction between the fluids and solids in many different applied fields, such as blood flow within arterial walls $[13,14]$, flow around the sails of a sailing boat [15], wind turbine [16], or deformation of the aircraft wing [17].

The relations between aerodynamic loads and structural behaviour for automobiles are still under investigations. The structure of the vehicle does not necessarily have to carry heavy pressure loads but still can be susceptible to a risk of fluttering because of the transient aerodynamic effects. According to Kesti and Olsson [18], a car which has a weak structure might deform when subjected to a high surrounding airspeed flow. It is pertinent to consider the deformation, as well as to analyse the effect of both aerodynamic forces and structural stresses. There are various methods available for FSI simulation. The selection of a particular method generally depends on the availability of the fluid and solid solver code, computation time, as well as the importance of the solid deformation process to the physics involved [19].

Numerous FSI studies have been performed on various parts of vehicles on road, for instance, car spoilers [20,21], convertible car roof [22], or even the whole car in braking motion [23]. Kesti and Olsson [18] demonstrated fluid-structure interaction analysis with partitioned approach in both oneway and two-way coupling to analyse the underbody panels. They stressed that the deforming mesh was the most crucial aspect to make a robust analysis. Tao et al., [24] conducted the fluid-structure interaction on the wind-induced vibrations of the windshield of van-body model bus at some different speeds. They demonstrated that the windshield structure deformation increased with the wind speed and had a maximum value when equilibrium was reached. They presented that the influence of aerodynamic drag coefficients of the model was different with and without the consideration of FSI, which showed that there was an error on the aerodynamic drag coefficient when the influence of the FSI was ignored.

However, there seems to be limited FSI studies in the prototype cars or vehicles with common materials due to the confidentiality of the past SEM teams. To the authors' best knowledge, FSI study on bio-degradable composite materials such as Flax fibre on aerodynamically shaped thin shell structure has never been reported in the literature. Therefore, this study provides the assessment of a new set of sustainable and economical materials with the one-way FSI analysis on a fully assembled SEM prototype car to ensure structural integrity of the car with Flax fibre composites.

\section{Methodology}

\subsection{Numerical FSI}

This study was performed numerically using a one-way static run partitioned approach. In this coupling method, ANSYS Fluent was used on the fluid side, and ANSYS Mechanical was used on the structure side. The fluid flow was calculated first until the desired convergence and thereafter, the resulted flow calculation was interpolated to the structural model at the interface. After that, the structural model calculation was iterated until convergence was achieved. 


\subsubsection{Partitioned approach}

A partitioned approach was used to carry out the research in this study. Two distinct solvers were used to solve the equations governing the flow and the displacement of the structure separately based on numerical solver and mesh discretisation. In this approach, sub-programmes were solved individually, in which the structural solution did not change concurrently when the fluid solution was computed. The software modularity was preserved as an existing flow. The structural solver was coupled, while the fluid and structure interfacial conditions were explicit. The aim of this approach was to combine the fluid-flow and structural algorithm to decrease the computational time. A mesh was connected by using a conforming mesh method [25]. Figure 1 below shows the step of a partitioned approach.

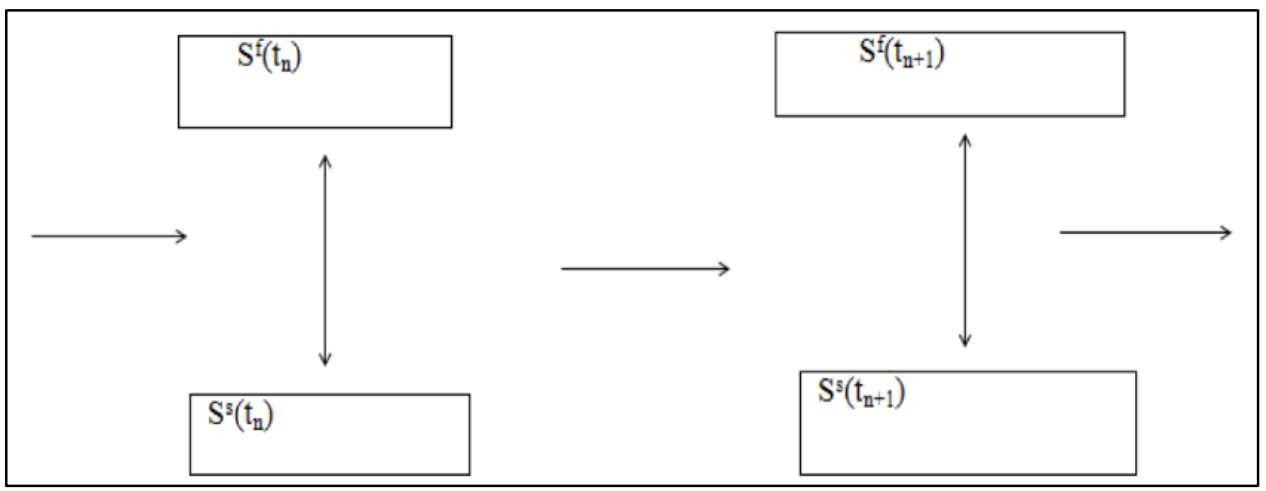

Fig. 1. Partitioned approach for FSI $\left(\mathrm{S}^{f}\right.$ and $\mathrm{S}^{S}$ denote fluid and structural solution respectively) [25]

Regardless of whether one-way or two-way coupling methods, the information for the solution was shared between the fluid-structure interfaces. Only the fluid pressure acting at the structure was transferred to the structure solver for one-way coupling analysis, while displacement of the structure was transferred to the fluid solver simultaneously for two-way coupling analysis. For this study, both one-way and two-way FSI have been performed. The results obtained from one-way coupling and two-way coupling show that there are no stark differences (the differences are less than an order) in the results for both total deformation and equivalent von Mises stress as shown in Table 1 . However, the time needed for the two-way FSI is about 10 days, roughly fifteen times more than that of oneway FSI, which takes about 17 hours. Hence, considering that both structural constraints are well below the safety threshold and the large computational costs for two-way FSI, only one-way coupling is discussed for the rest of the paper.

\section{Table 1}

Result comparison between one-way and two-way coupling

\begin{tabular}{lllll}
\hline Distance $(\mathrm{m})$ & \multicolumn{2}{l}{ Total Deformation } & \multicolumn{2}{l}{ Equivalent von Mises stress } \\
\cline { 2 - 5 } & Max value $(\mathrm{m})$ & Region & Max value $(\mathrm{Pa})$ & Region \\
\hline One-way & $6.619 \times 10^{-6}$ & Window & 32357 & Shell \\
Two-way & $7.245 \times 10^{-6}$ & Window & 54470 & Shell \\
\hline
\end{tabular}

\subsection{FSI Modelling}

The fluid problem is described in an arbitrary Lagrangian-Eulerian (ALE) framework since the fluid's domain is changing with the interface movement, while the purely Lagrangian approach is employed for the structure's domain. Generally, in the FSI system, three sets of variables are aimed 
to be solved which are the fluid velocity $\mathbf{u}(\mathbf{x}, \mathbf{t})$, the fluid mesh velocity $\mathbf{w}(\mathbf{x}, \mathbf{t})$ and the structure displacement $\eta(\mathbf{X}, \mathrm{t})[26]$.

In the fluid model, the fluid is assumed to be incompressible and Newtonian. Hence, it is described by the incompressible Navier-Stokes equation in the ALE framework,

$\frac{\partial \boldsymbol{u}}{\partial x}+(\boldsymbol{u}-\boldsymbol{w}) \cdot \nabla \boldsymbol{u}=-\frac{\nabla \mathrm{p}}{\rho_{f}}+v \nabla^{2} \boldsymbol{u}$

$\nabla \cdot \boldsymbol{u}=0$,

combined with the Dirichlet boundary conditions on the interface,

$\boldsymbol{u}=\frac{\partial \eta}{\partial t}$

where $\mathbf{u}=$ boundary, $\mathbf{w}=$ mesh velocity, $\mathrm{p}=$ pressure, $\rho_{f}=$ fluid density, and $v=$ kinematic viscosity.

In structure domain, Lagrangian approach is adopted and written as:

$\rho_{S} \frac{\partial^{2} \eta}{\partial t^{2}}-\operatorname{div}(\mathbf{S})=\rho_{S} \mathbf{f}$

with the Neumann boundary condition at the interface

$\mathbf{S} \boldsymbol{n}_{\mathbf{s}}=-\left[-\mathrm{pl}+\rho_{f} v\left(\nabla \boldsymbol{u}+(\nabla \boldsymbol{u})^{T}\right)\right] \boldsymbol{n}_{f}$,

where $\mathbf{f}=$ body load, $\rho_{s}=$ structure density, $\mathbf{n}_{\mathbf{s}}=$ normal vector from the structure domain, $\boldsymbol{n}_{f}=$ normal vector of fluid subdomain pointing outward on the interface, $S=$ second Piola-Kirchhoff stress tensor which is given by

$\mathbf{S}=\frac{\varsigma E}{2(1+\varsigma)(1-2 \varsigma)}\left[\operatorname{tr}\left(\frac{\partial \eta}{\partial X}+\frac{\partial \eta^{T}}{\partial X}\right)\right]+\frac{E}{2(1+\varsigma)}\left(\frac{\partial \eta}{\partial X}+\frac{\partial \eta^{T}}{\partial X}\right)$.

To integrate in time, the first order Backward Differentiation scheme is considered

$\rho_{S} \frac{\delta \eta^{n}-\delta \eta^{n-1}}{\Delta t}-\operatorname{div}\left(\mathbf{S}\left(\eta^{n-1 / 2}\right)\right)=\rho_{S} \mathbf{f}^{n}$

$\delta \eta^{n}=\frac{\eta^{n}-\eta^{n-1}}{\Delta t}$

$\eta^{n-1 / 2}=\frac{\eta^{n}+\eta^{n-1}}{\Delta t}$

It should be noted that the temporal terms are referred to pseudo-time as the simulations are of steady flows. To enforce the continuity of the normal stresses at the interface,

$\mathbf{S}\left(\eta^{n-1 / 2}\right) \mathbf{n}_{\mathbf{s}}=-\left[-p^{n-1} \mathbf{I}+\rho_{f} v\left(\nabla \boldsymbol{u}^{n-1}+\left(\nabla \boldsymbol{u}^{n-1}\right)^{T}\right)\right] \boldsymbol{n}_{f}$ 


\subsubsection{Governing equations}

On the solution of the fluid side, the Navier-Stokes equation, written in Einstein summation convention is given by

$\rho \frac{\partial u_{i}}{\partial t}+\rho\left(\frac{\partial u_{i} u_{j}}{\partial x_{j}}\right)=-\frac{\partial \mathrm{p}}{\partial x_{i}}+\eta \frac{\partial}{\partial x_{j}}\left(\frac{\partial u_{i}}{\partial x_{j}}+\frac{\partial u_{j}}{\partial x_{i}}-\frac{2}{3} \frac{\partial u_{k}}{\partial x_{k}} \delta_{i j}\right)$

Low Reynolds Number k- $\omega$ Turbulence model was used in this study as it is widely used for simulating complex flow phenomena in many engineering applications due to its simplicity and effectiveness [27]. Using Reynolds averaging, the Reynolds-Averaged-Navier-Stokes equation is given by

$\rho \frac{\partial \overline{u_{l}}}{\partial t}+\rho\left(\frac{\partial \overline{u_{l}} \overline{u_{j}}}{\partial x_{j}}\right)=-\frac{\partial \overline{\mathrm{p}}}{\partial x_{i}}+\eta \frac{\partial}{\partial x_{j}}\left(\frac{\partial \overline{u_{l}}}{\partial x_{j}}+\frac{\partial \overline{u_{j}}}{\partial x_{i}}-\frac{2}{3} \frac{\partial \overline{u_{k}}}{\partial x_{k}} \delta_{i j}\right)-\rho\left(\frac{\partial}{\partial x_{j}} \overline{u_{\imath}^{\prime} u_{\jmath}^{\prime}}\right)$

where $\overline{u_{\imath}{ }^{\prime} u_{\jmath}{ }^{\prime}}$ is the Reynolds stress tensor which is calculated with the turbulence model. These equations are solved using a finite volume approach.

On the solution of the structure side, it is based on the impulse conservation and is solved numerically using a finite element approach [28]. The equation is given by

$M \cdot \vec{u}+\mathrm{C} \cdot \vec{u}+\mathrm{K} \cdot \vec{u}=\vec{F}$,

where $\vec{u}, \vec{u}$ and $\vec{u}$ denote the vibration amplitude of the point, the $1^{\text {st }}$ order partial derivative and $2^{\text {nd }}$ order partial derivative with respect to the time, $\mathrm{t}$ respectively. $\mathrm{M}, \mathrm{C}, \mathrm{K}$ and $\vec{F}$ are mass, damping coefficient, spring (stiffness) constant, and vector of the externally applied forces, respectively. To integrate in time, Newmark time integration method is used to solve Eq. (13) at discrete time steps. The Newmark method uses finite-difference expansions for the time interval.

Note that the fluids pressure acting on the structure is transferred to the structure solver in a one-way explicit coupling in this study. In FEA, the global stiffness matrix depends on the geometry and material selection. Theoretically, two different materials with the same geometry under a load exhibit the same stresses. The model with the lower Young's Modulus might exhibit different local deformations.

\subsection{SEM Car Model}

Some simplifications were applied on the fully assembled SEM prototype car to remove extremely narrow spaces which are capable to degrade the mesh quality tremendously. For instance, the spaces between the rims and the wheels were removed, and the wheels were modified to fill up the small spaces between the ground and the wheels. Other small details in the real car construction, such as screws, small gaps between parts connections were also removed. Figure 2 shows a simplified version from the actual design of the fully assembled SEM prototype car. 


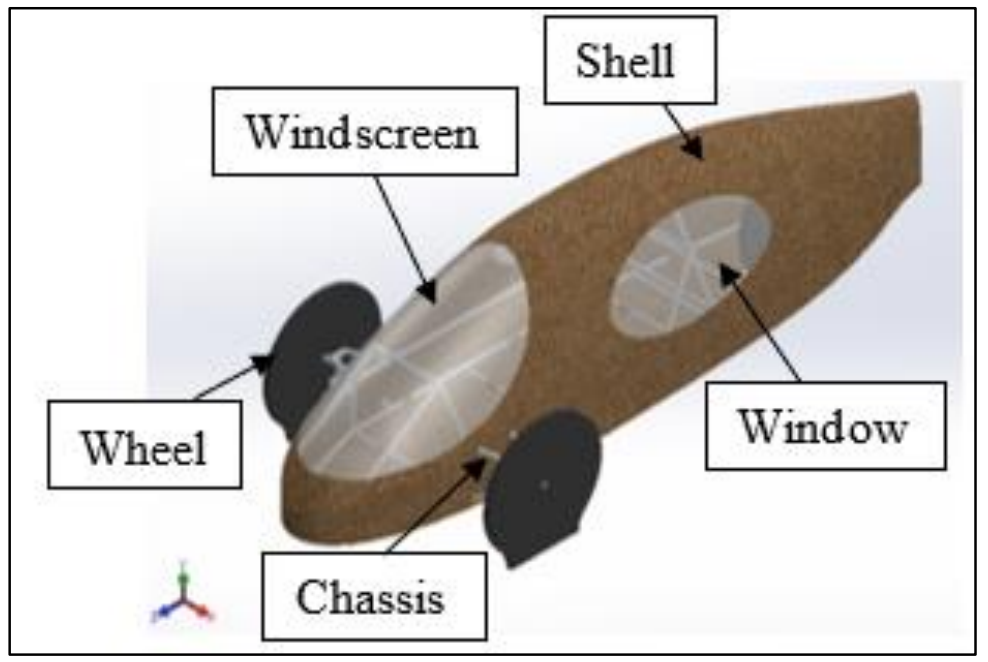

Fig. 2. Prototype car in simplified version

\subsubsection{Fluids modelling}

The prototype car model was imported to ANSYS 19.1 WORKBENCH as a STEP file. The domains or control volumes as shown in Figure 3 were modelled using Design Modeler. The flow domains were divided into smaller refined domains to ensure a complete picture of the fluid flow in the entire domain. The geometry had one symmetry plane (YZ plane) and was therefore likely to have a symmetrical flow field. A half model (one symmetry plane) was applied in the domains.

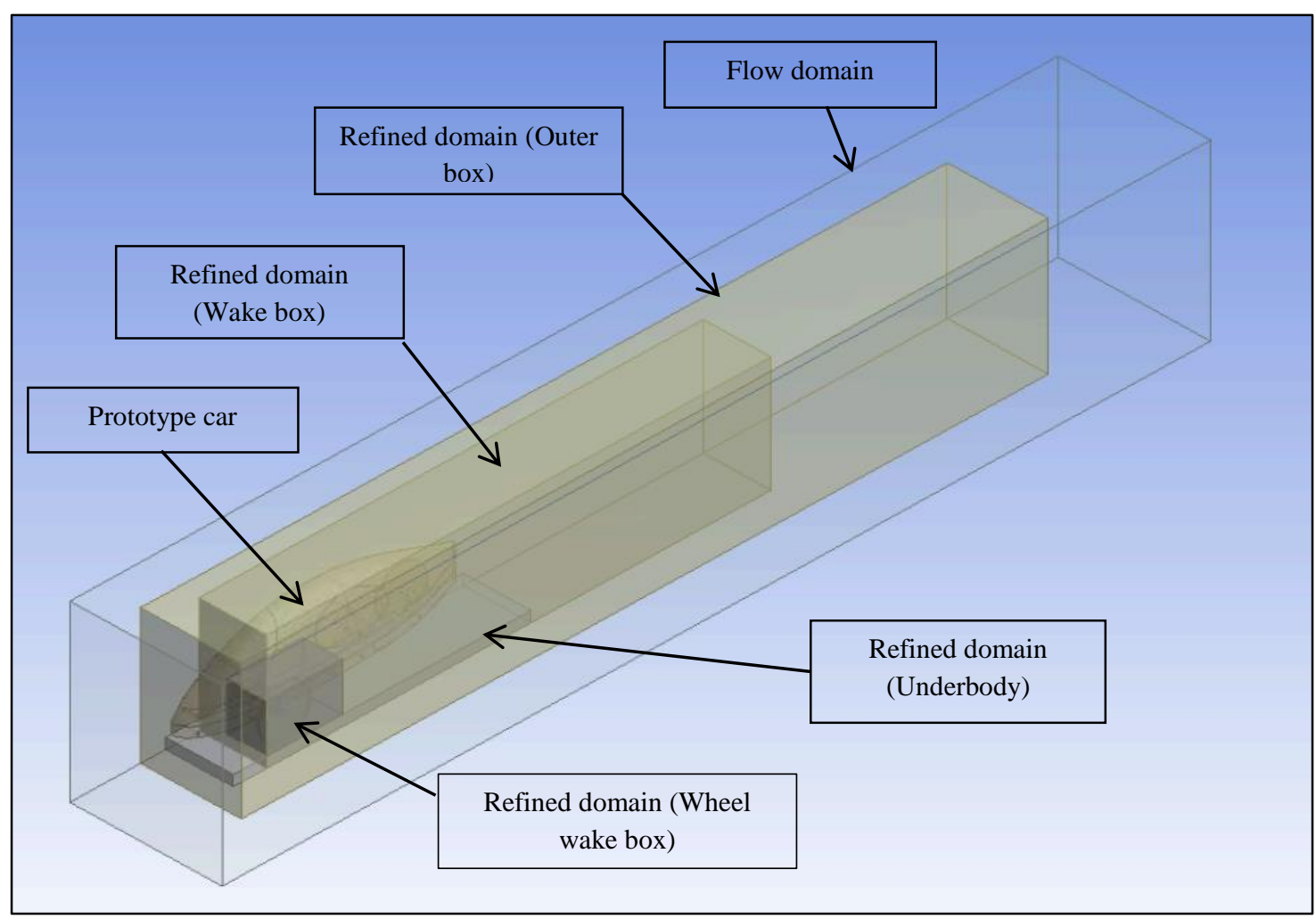

Fig. 3. CFD control volume

The mesh generation step is shown in Table 2 and the solver set up for CFD is shown in Table 3. 
Table 2

Meshing control set up (CFD)

\begin{tabular}{ll}
\hline Type & Details \\
\hline \multirow{2}{*}{ Element sizing } & Geometry: Prototype car faces \\
& Element size: 0.02682m \\
& Method: Tetrahedrons \\
Patch independent & Max element size: $0.6705 \mathrm{~m}$ \\
& Min size limit: 0.02682m \\
& Geometry: Flow domain \\
& Body of influence: Outer box \\
& Element size: 0.1609m \\
& Geometry: Flow domain \\
& Body of influence: Underbody \\
& Element size: 0.02682m \\
& \\
& Geometry: Flow domain \\
& Body of influence: Wake box \\
& Element size: $0.1019 \mathrm{~m}$ \\
\hline
\end{tabular}

Table 3

Solver set up (CFD)

\begin{tabular}{lll}
\hline Boundary Conditions & & \\
\hline & Velocity Magnitude (ms-1) & 60 \\
Velocity-inlet & Turbulent Intensity (\%) & 0.2 \\
& Turbulent Viscosity Ratio & 10 \\
& Z-component of flow direction & -1 \\
& Relative Gauge Pressure (Pas) & 0 \\
Pressure-outlet & Backflow Turbulent Intensity (\%) & 5 \\
& Backflow Turbulent Viscosity Ratio & 10 \\
Solution Methods & & \\
\hline Model & SST k-omega & \\
Options & Low-Re Corrections \\
Scheme & Coupled \\
Gradient & Least Squares Cell Based \\
$\begin{array}{l}\text { Pressure } \\
\text { Momentum }\end{array}$ & $2^{\text {nd }}$ order \\
$\begin{array}{l}\text { Turbulent kinetic energy } \\
\text { Specific Dissipation Rate } \\
\text { Initialize solution }\end{array}$ & $2^{\text {nd }}$ order upwind & \\
\hline
\end{tabular}

\subsubsection{Structural modelling}

Figure 4 presents the fully assembled SEM prototype car geometry that was used in ANSYS Mechanical. The mechanical properties data of the selected materials were incorporated into the ANSYS Engineering Data tool. A symmetry plane, which was YZ plane, was created on the model using a symmetry tool to generate half of the original geometry. The material sets were then assigned to each specific car's component. As the wheels were not in the concern of analysis, the wheels materials were set the same as the chassis support. The FEA model was meshed with the following setup as shown in Table 4. 


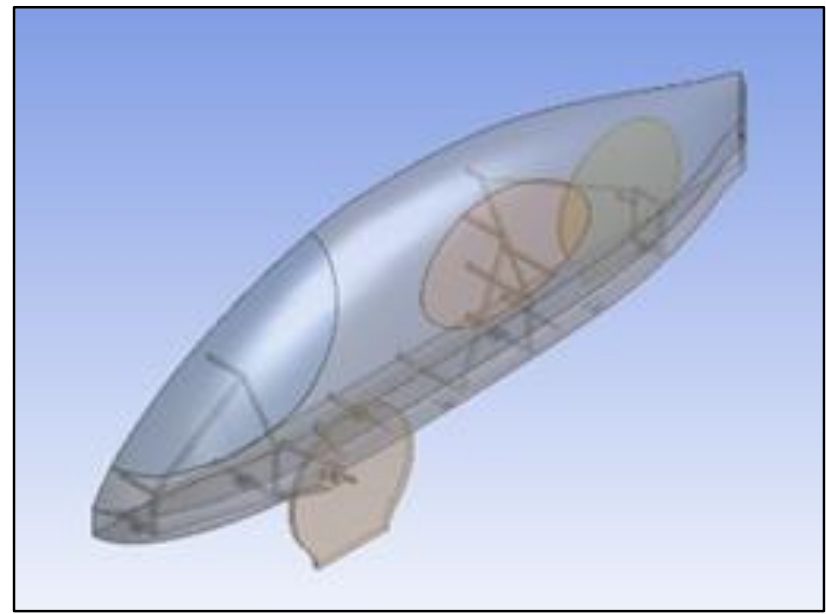

Fig. 4. Prototype car geometry in structural model

\section{Table 4}

Meshing control set up (FEA)

\begin{tabular}{|c|c|}
\hline \multicolumn{2}{|c|}{ Global Mehing Control } \\
\hline Element Order & Linear \\
\hline \multicolumn{2}{|c|}{ Local Meshing Control } \\
\hline \multirow{3}{*}{ Element Sizing } & $\begin{array}{l}\text { Geometry: Wheels } \\
\text { Element Size: } 0.02 \mathrm{~m}\end{array}$ \\
\hline & $\begin{array}{l}\text { Geometry: Shell, Windscreen, } \\
\text { Windows } \\
\text { Element Size: } 0.002 \mathrm{~m}\end{array}$ \\
\hline & $\begin{array}{l}\text { Geometry: Chassis } \\
\text { Element Size: } 0.01 \mathrm{~m}\end{array}$ \\
\hline
\end{tabular}

On the definitions of boundary conditions, the bases of the wheels' surfaces were set as fixed support. The faces in the $y-z$ symmetry plane were selected as frictionless support. Figure 5 presents the structural boundary conditions. The mapping pressure data of the prototype car surface from the CFD solver were imported into the Structure solver. In the mapping settings, triangulation and distance based average methods were applied.
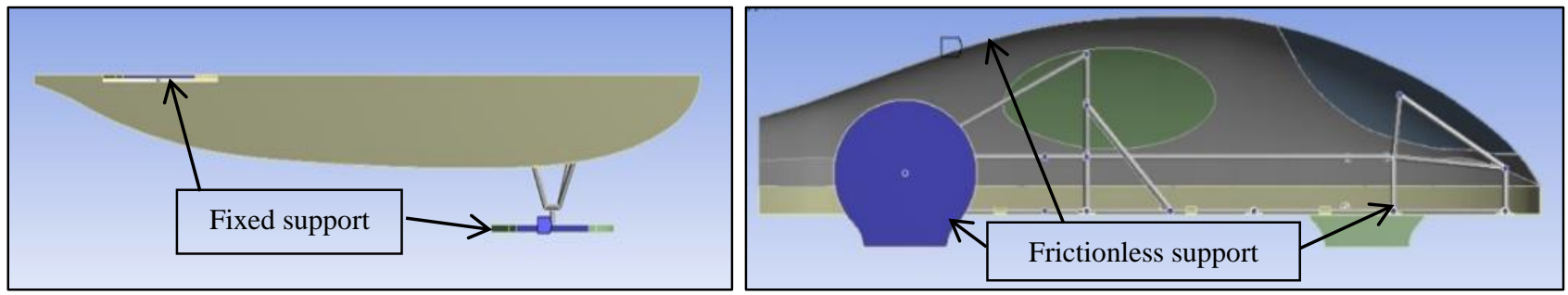

Fig. 5. Structural boundary conditions

\subsubsection{Mesh quality and grid independence test (GIT)}

The accuracy of the FSI coupled simulations depends on the spatial and temporal discretisation of the constituent fluids and structural models. In this study, a mesh dependency study was performed to verify that the fluid model and structure model provided a mesh independent solution, respectively. On the fluid side, the steady-state CFD analysis was carried out on the Ahmed body 
model with six different grid densities but similar settings in the use of Low-Reynolds-Number SST k$\omega$ model [29]. The fluid mesh dependency study result is shown in Figure 6 and Table 5.

The final mesh chosen was the mesh elements around 3.5 million, (highlighted in yellow); to be more specific, it was 3713677 cells with 5295232 number of nodes. It is proven to have the best solving time to data accuracy ratio as it has the lowest percentage error in drag coefficient value at $6.608 \%$ when it is compared to experimental result, and the difference with the next mesh (4.5 million cells) is only $0.6335 \%$. Finite volume methods are very sensitive to grid quality [30]. The generated mesh has a good quality with a maximum skewness of 0.88619 , an average skewness around 0.14053 and an average aspect ratio of 2.0015 of which is within the recommended range $[31,32]$. Figure 7 presents the Fluent unstructured mesh that was used in this study.

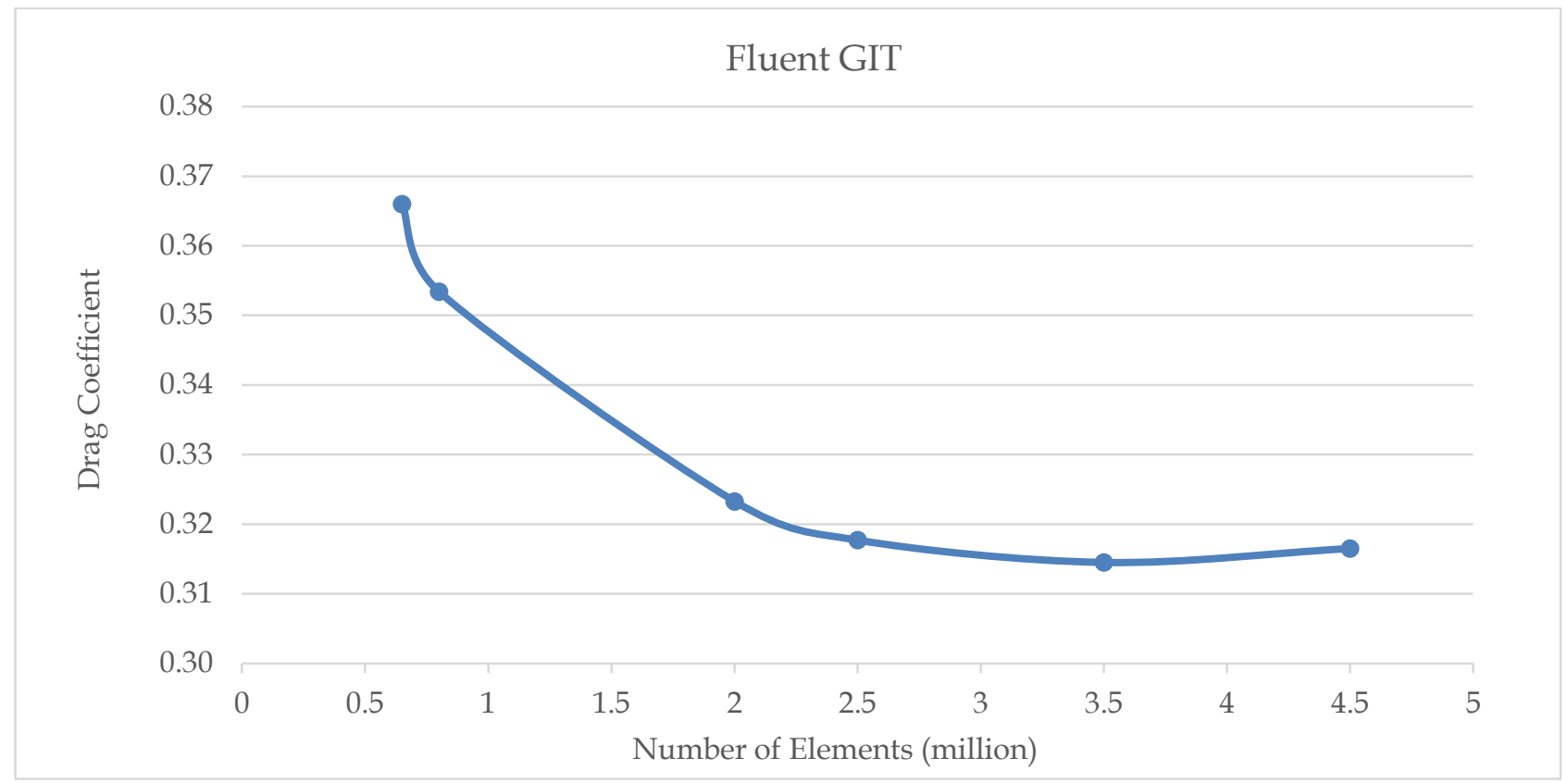

Fig. 6. Fluent GIT graph result

Table 5

Fluent GIT result

\begin{tabular}{lllll}
\hline Mesh size & $C_{D}$ & $\begin{array}{l}\text { Relative } \\
\text { error (\%) }\end{array}$ & Experiment [27] & $\begin{array}{l}\text { Relative error with } \\
\text { experiment (\%) }\end{array}$ \\
\hline $0.65 \mathrm{~m}$ & 0.3660 & 3.5683 & & 24.068 \\
$0.8 \mathrm{~m}$ & 0.3534 & 9.3139 & & 19.793 \\
$2.0 \mathrm{~m}$ & 0.3233 & 1.7564 & \multirow{2}{*}{0.295} & 9.586 \\
$2.5 \mathrm{~m}$ & 0.3177 & 1.0191 & & 7.695 \\
$3.5 \mathrm{~m}$ & 0.3145 & 0.6335 & & 6.608 \\
$4.5 \mathrm{~m}$ & 0.3165 & - & & 7.288 \\
\hline
\end{tabular}

On the structure side, the steady-state one-way coupling analysis was carried out on the prototype car model with seven different structure grid densities. The mesh of the structural model was generated with its boundaries similar to those of the fluid mesh in order to minimise the errors caused during the load data exchange between the two solvers. The mesh dependency study is as shown in the Figure 8 and Table 6. 


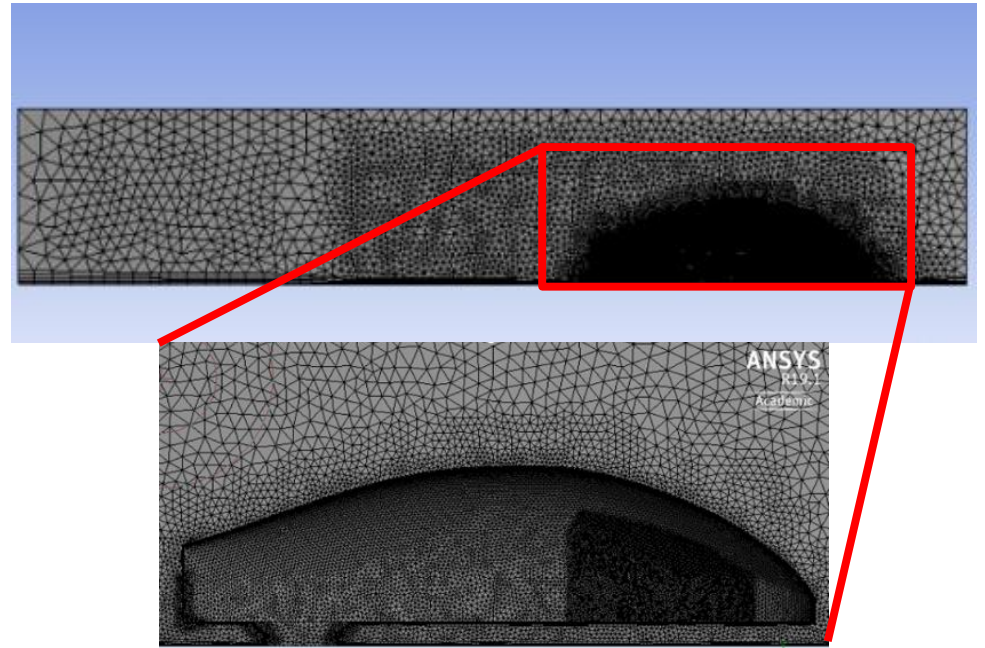

Fig. 7. CFD mesh set up

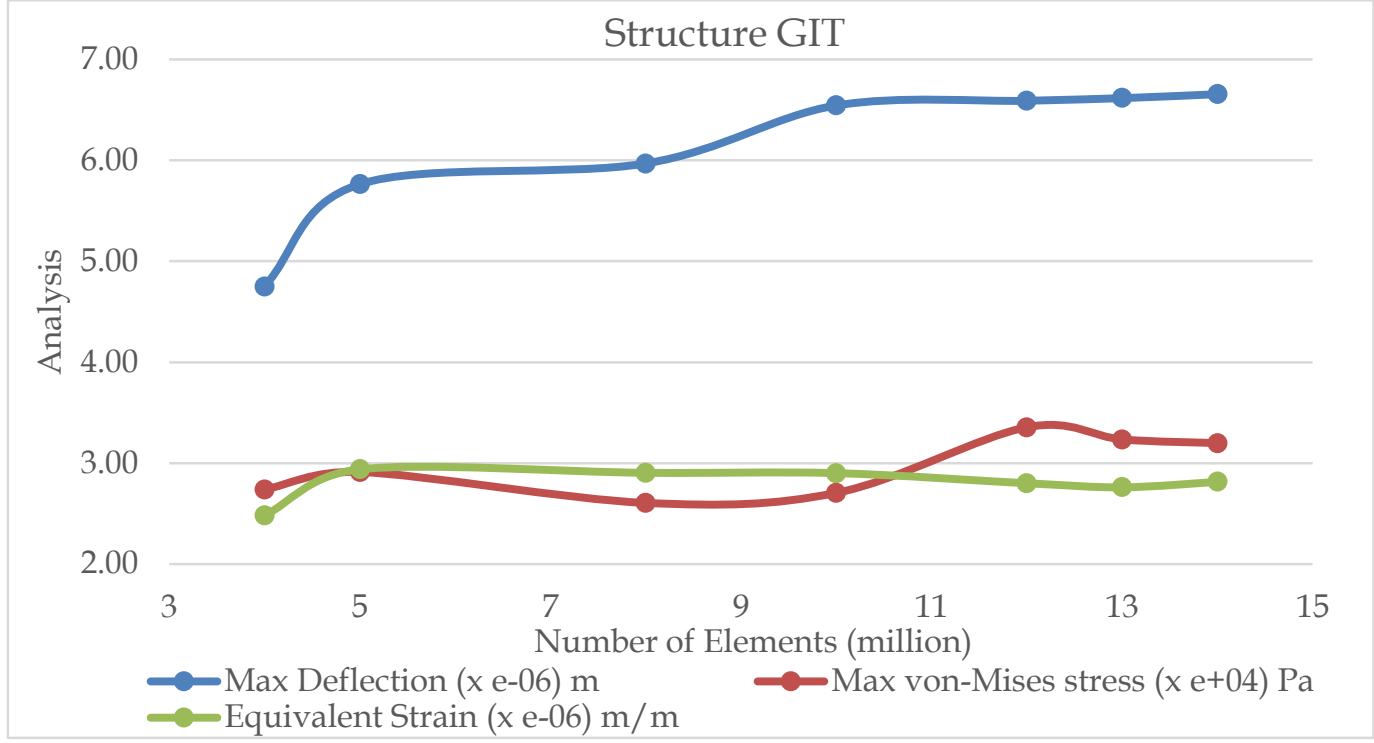

Fig. 8. Structure GIT graph result

Table 6

Structure GIT result

\begin{tabular}{lllllll}
\hline $\begin{array}{l}\text { Mesh } \\
\text { size }\end{array}$ & $\begin{array}{l}\text { Max deflection } \\
\left(\times 10^{-6}\right) \mathrm{m}\end{array}$ & $\begin{array}{l}\text { Relative } \\
\text { error }\end{array}$ & $\begin{array}{l}\text { Max von-Mises } \\
\text { stress }\left(\times 10^{4}\right) \mathrm{Pa}\end{array}$ & $\begin{array}{l}\text { Relative } \\
\text { error }\end{array}$ & $\begin{array}{l}\text { Max equivalent } \\
\text { strain }\left(\times 10^{-6}\right) \mathrm{m} / \mathrm{m}\end{array}$ & $\begin{array}{l}\text { Relative } \\
\text { error }\end{array}$ \\
\hline $4 \mathrm{~m}$ & 4.751 & 17.59 & 2.739 & 5.965 & 2.483 & 15.54 \\
$5 \mathrm{~m}$ & 5.765 & 3.439 & 2.912 & 11.75 & 2.940 & 1.187 \\
$8 \mathrm{~m}$ & 5.970 & 8.793 & 2.606 & 3.667 & 2.905 & 0.117 \\
$10 \mathrm{~m}$ & 6.546 & 0.714 & 2.705 & 19.39 & 2.902 & 3.554 \\
$12 \mathrm{~m}$ & 6.593 & 0.391 & 3.356 & 3.721 & 2.802 & 1.463 \\
$13 \mathrm{~m}$ & 6.619 & 0.589 & 3.236 & 1.135 & 2.762 & 1.914 \\
$14 \mathrm{~m}$ & 6.658 & - & 3.199 & - & 2.816 & - \\
\hline
\end{tabular}

The final structure mesh chosen was the mesh elements around 13 million, (highlighted in yellow); to be more specific, it was 13386927 cells with 3411160 number of nodes. It is proven to have the best solving time to data accuracy ratio as it has the lowest percentage error in relative to the next mesh (14 million cells). The generated mesh has a good quality with a maximum skewness of 0.85177, an average skewness around 0.26436 and an average aspect ratio of 1.9574. Figure 9 presents the Structural unstructured mesh that was used in this study. 


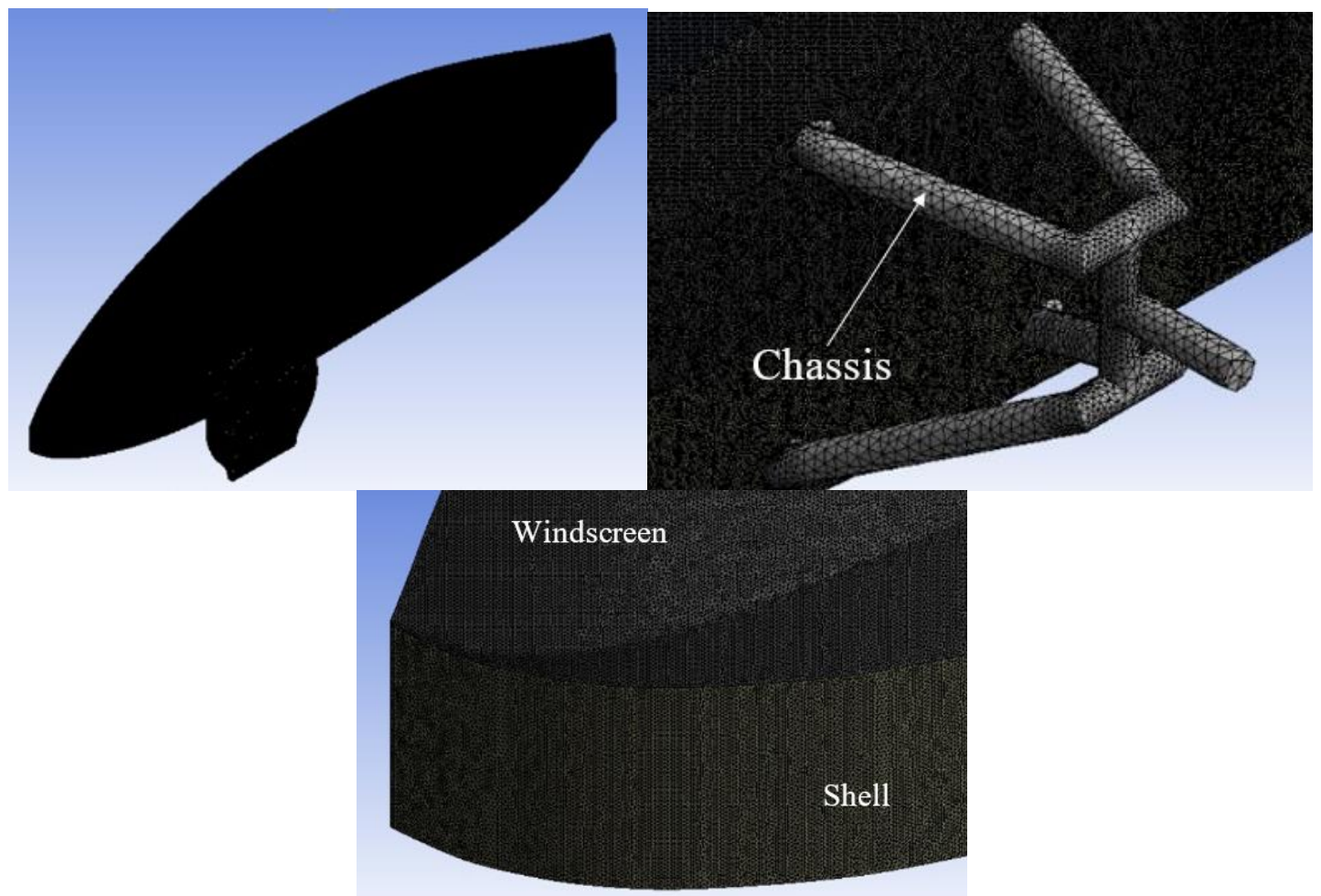

Fig. 9. Structural mesh set up

\subsection{Prototype Car Material}

The proposed materials for the prototype car used in this study are shown in Table 7, in comparison to the common materials used in SEM competition. The material set was proposed based on the consideration on weight (density), strength (ability to withstand the stresses without yielding), economy, and fabrication ease. Flax fibre composite is one of the preferred materials because of the propensity in environmental impact concern with respect to the SEM competition. Aluminium alloy and acrylic material were preferred due to the economical concern in fabrication process, plus mechanical strength of both materials was deemed to be sufficient for this study. Table 8 shows the mechanical properties of selected materials.

Table 7

SEM prototype car materials

\begin{tabular}{lll}
\hline Car components & Proposed materials & Common materials \\
\hline Shell & Flax fibre composite & GFRP \\
Chassis & Aluminium alloy & CFRP \\
Windscreen and window & Acrylic & Polycarbonate \\
\hline
\end{tabular}

Table 8

SEM prototype car materials [33-35]

\begin{tabular}{llllll}
\hline & $\begin{array}{l}\text { Density, } \rho \\
\left(\mathrm{kgm}^{-3}\right)\end{array}$ & $\begin{array}{l}\text { Modulus of } \\
\text { Elasticity, E (GPa) }\end{array}$ & $\begin{array}{l}\text { Poisson } \\
\text { Ratio, } v\end{array}$ & $\begin{array}{l}\text { Yield Strength, } \\
\mathrm{S}_{\mathrm{y}}(\mathrm{MPa})\end{array}$ & $\begin{array}{l}\text { Ultimate Tensile } \\
\text { Strength, } \mathrm{Su}(\mathrm{MPa})\end{array}$ \\
\hline Flax Fibre Composite & 1494 & 17.5 & 0.355 & 372.8 & 469.7 \\
Aluminium Alloy & 2770 & 71 & 0.33 & 280 & 310 \\
Acrylic & 1180 & 2.69 & 0.395 & 62.4 & 67.1 \\
\hline
\end{tabular}




\section{Results}

\subsection{Computational Fluid Dynamics Solution}

Table 9 presents the reference values and drag results of the fully assembled SEM prototype car. Note that the car is travelling at $25 \mathrm{~km} / \mathrm{hr}$. The drag coefficient, viscous drag, pressure drag, and total drag values were not treated as constant values as these were calculated as the average of the oscillating drag parameters. The results involve transient behaviour in the CFD simulation. The drag of the prototype car is dominated by the pressure drag, contributing to $66 \%$ of the drag while the rest is due to viscous drag. The high-pressure drag is due to complex car components, such as wheels and chassis which cause the body shell to be less streamlined and hence heavily distort the incoming smooth flow.

\begin{tabular}{|c|c|}
\hline Parameters & Values \\
\hline$C_{D}$ & 0.2473 \\
\hline Surface Area & $8.005 \mathrm{~m}^{2}$ \\
\hline Frontal Area & $0.3928 \mathrm{~m}^{2}$ \\
\hline Viscous Drag & $0.9696 \mathrm{~N}$ \\
\hline Pressure Drag & $1.899 \mathrm{~N}$ \\
\hline Total Drag & $2.869 \mathrm{~N}$ \\
\hline
\end{tabular}

A more comprehensive visualisation on the flow fields around the fully assembled SEM prototype car is shown in Figure 10.

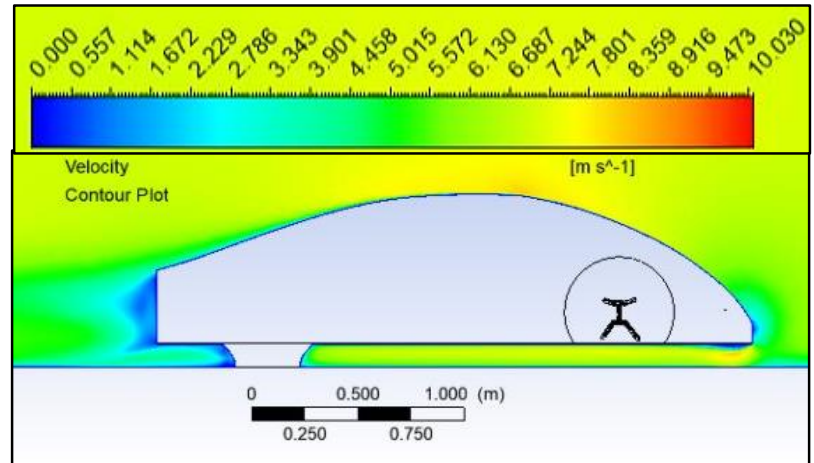

(a)

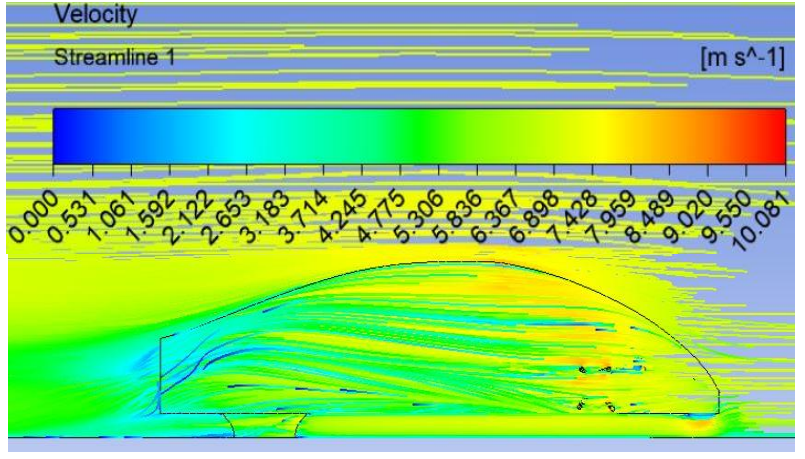

(b)

Fig. 10. Flow contours around fully assembled SEM prototype car, (a) velocity flow field at symmetry plane, (b) flow streamline

Figure 10(a) displays the velocity flow field at the symmetry plane. It should be noted that the car is moving towards to right of the diagram and only the rear wheel profile appears in the symmetry plane. With a teardrop like shape for the upper section of the car excluding the rear end, the flow over the car is akin to that of an aerofoil. The stagnation point is visible at the vertical cut-off car nose and the flow is accelerated over the top of the car and gradually slowed down by the adverse pressure gradient. Flow separation is observed at the aft of the car as well as the aft of the rear wheel as indicated by the contours of blue areas. According to the Figure 10(b), there are some swirling streamlines with low velocities (also known as vortex line) along the downstream of the front wheel and chassis support, which are formed due to the complex shapes of the chassis support. Near to the 
aft of the car, it is observed that the streamlines follow the shape of the car which converge at the rear end of the car before they leave the car and continue downstream.

Figure 11 shows the pressure flow field around prototype car at the symmetrical plane. It can be observed that the gauge pressure values indicated in the legend show that the maximum pressure experienced by the prototype car is around $31.30 \mathrm{~Pa}$. This happens around the vertical cut-off nose design which obstructed the incoming flow to the stagnation region as observed in Figure 10. It is also noted that the favourable pressure gradient and adverse pressure gradient regions are also consistent with the variation of velocities observed in Figure 10.

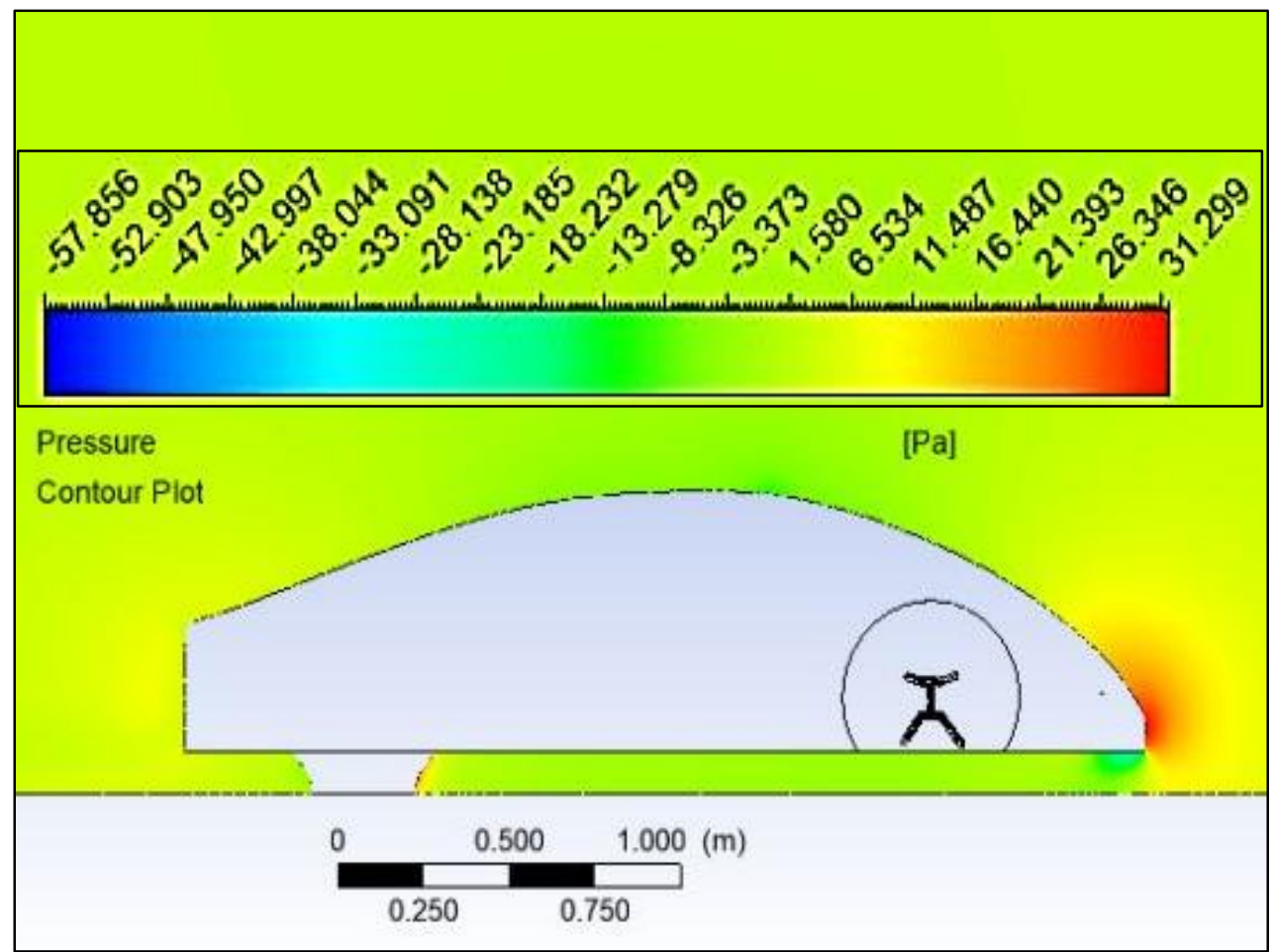

Fig. 11. Pressure flow field distribution

\subsection{Mapping Data Transfer}

Figure 12(a) shows the surface pressure distribution of prototype car in CFD solver and Figure 12(b) presents the overall equivalent pressure distribution in Structure solver. Comparing both the surface pressure distributions, both solvers have a larger pressure region that occurs at the leading edge of the prototype car. Tension loads, represented by negative pressure values, are outward pressures, while compressive loads, represented by positive values, are inward pressures experienced by the surfaces [36]. There are slight differences in the pressure distribution values between two solvers because the structural nodal values are mapped by linear interpolation from the CFD nodal results. Figure 13 depicts the surface pressure distribution according to the prototype car components. 


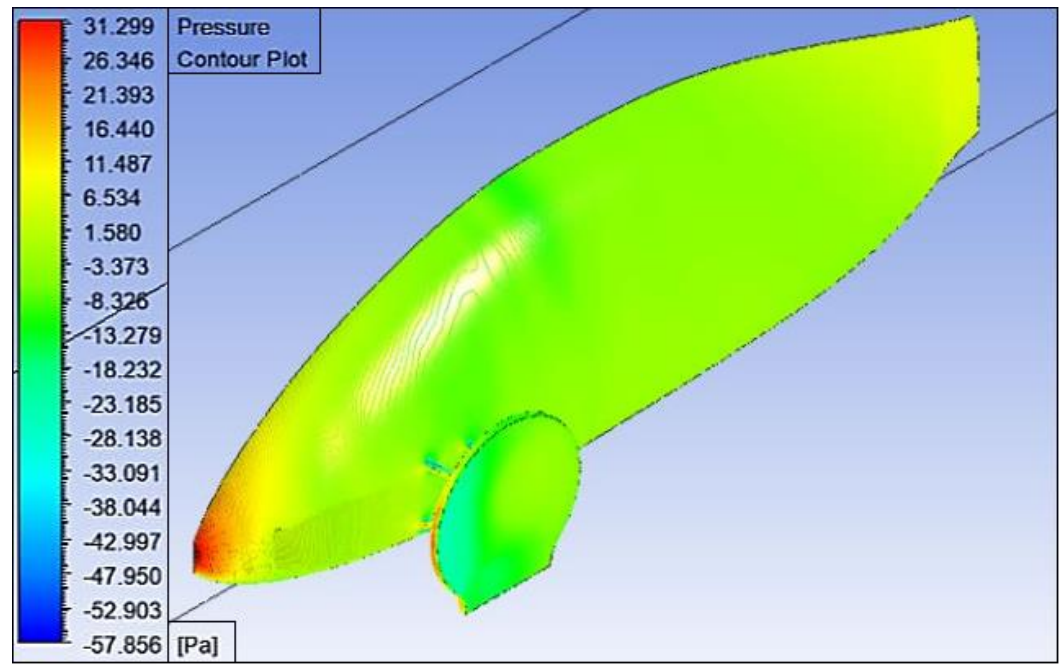

(a)

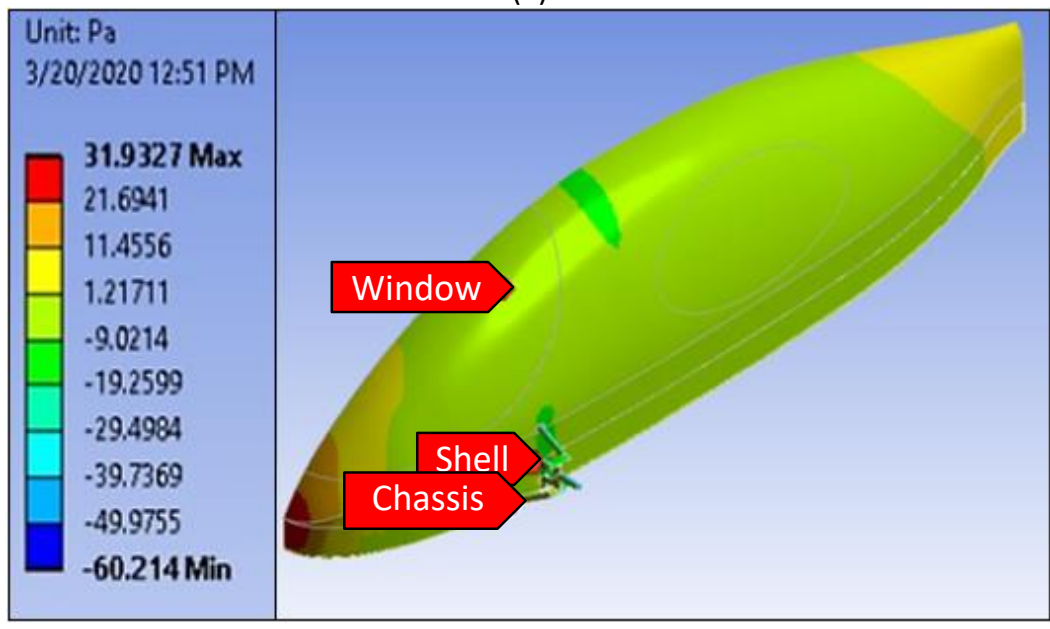

(b)

Fig. 12. Pressure flow field distribution, (a) in CFD solver, (b) in Structure solver

\subsection{Finite Element Solution}

The assessment of the car structure is an integral part of the design phase to ensure that the prototype car is capable to perform with the exerted pressure loads while travelling at $25 \mathrm{~km} / \mathrm{hr}$ without undesirable result. The total deformation, equivalent von Mises stress and equivalent strain are considered as the important factors in this study to assess vehicle failure.

Figure 14 presents the results of the total deformation experienced by the prototype car due to the applied pressure loads from the steady flow field. As it can be seen in the figure, the maximum deformation is about $6.619 \mathrm{e}-6 \mathrm{~m}$ on the window region. The window is subjected to the compression loading and thus, the deformation is due to the lower mechanical properties of the acrylic material in comparison with flax fibre composite and aluminium alloy. Besides that, the area of the prototype car shows that the curvature area is greatly subjected to the significant deflection in comparison with other areas. Saghafi [37] remarked that the curved panels respond to loads with a higher maximum deflection than the flat panels. However, the deformation is small enough to be considered negligible and safe for the driver who travels with a car's speed of $25 \mathrm{~km} / \mathrm{h}$.

Moreover, since the deformations are of order of micrometre while the car is of order of metres, there is no necessity to run a cost demanding two-way FSI as the changes in fluid flow are minimal and do not affect the final structural results. 


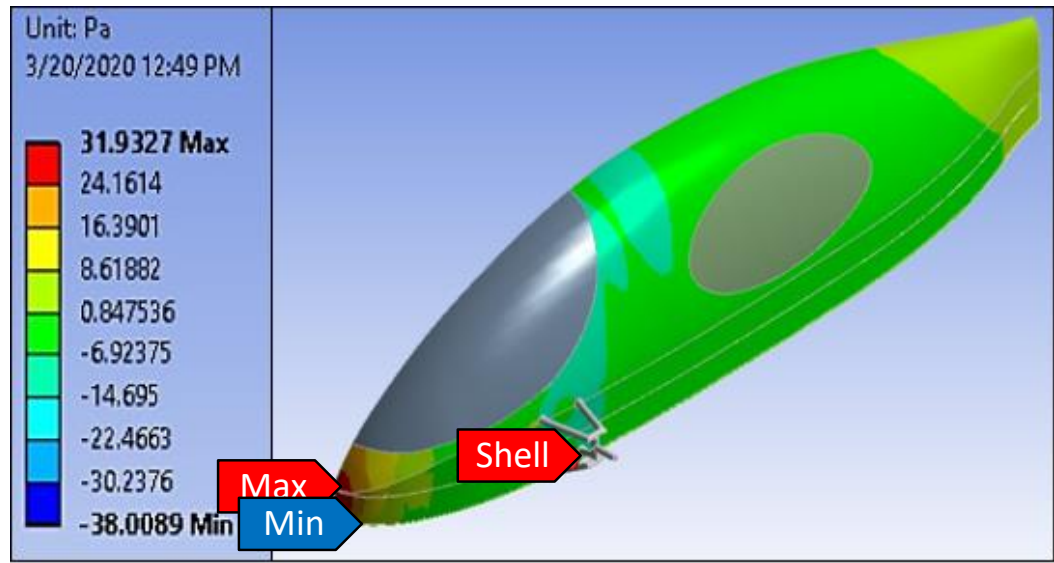

(a)

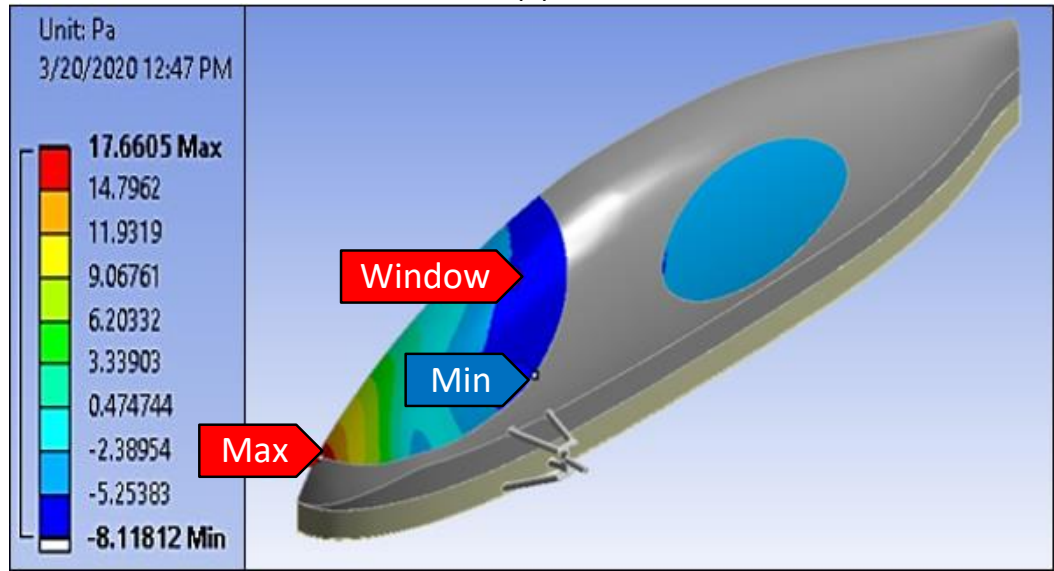

(b)

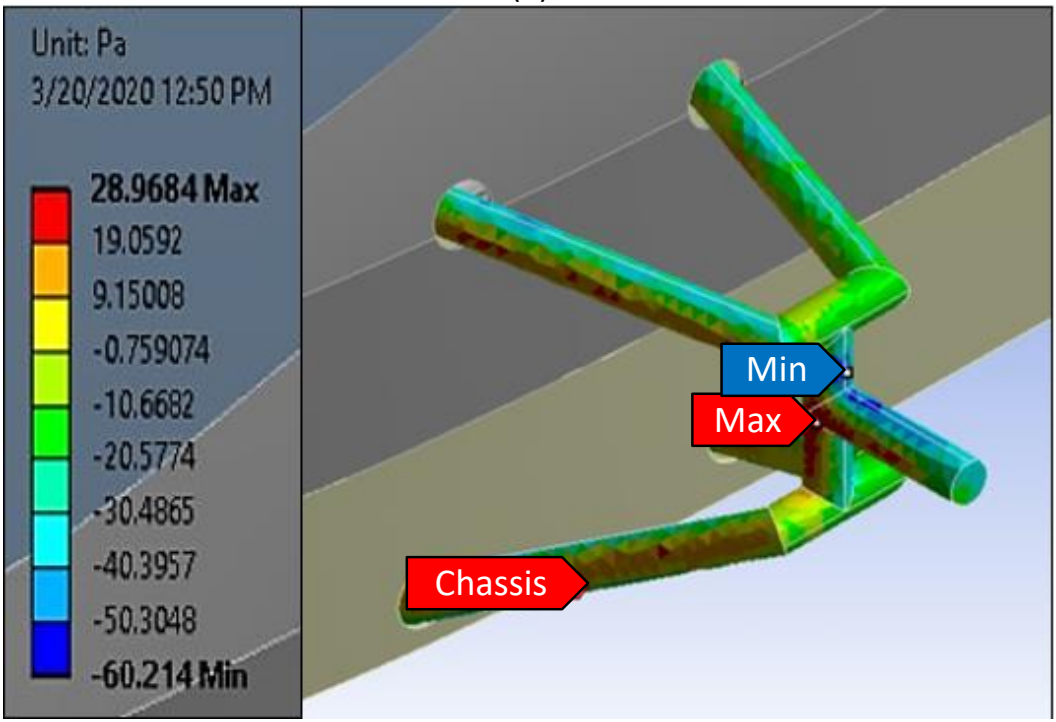

(c)

Fig. 13. Respective car's surface pressure distribution, (a) shell, (b) windscreen and window, (c) chassis in Structure solver 


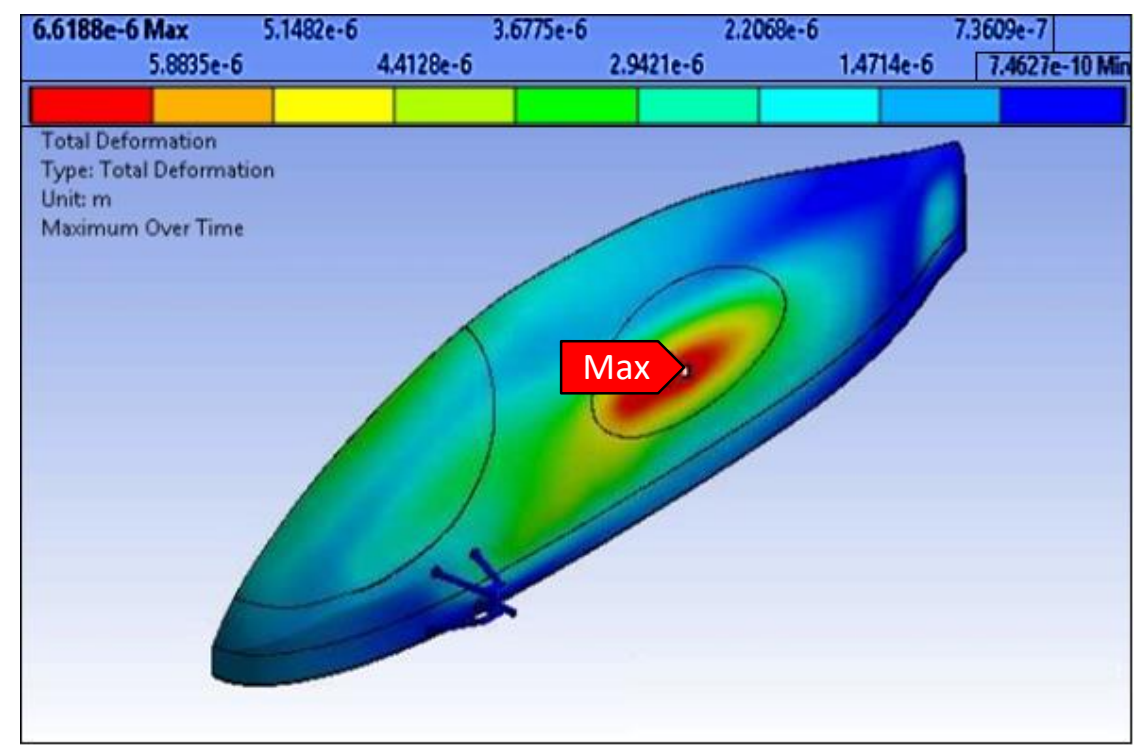

(a)

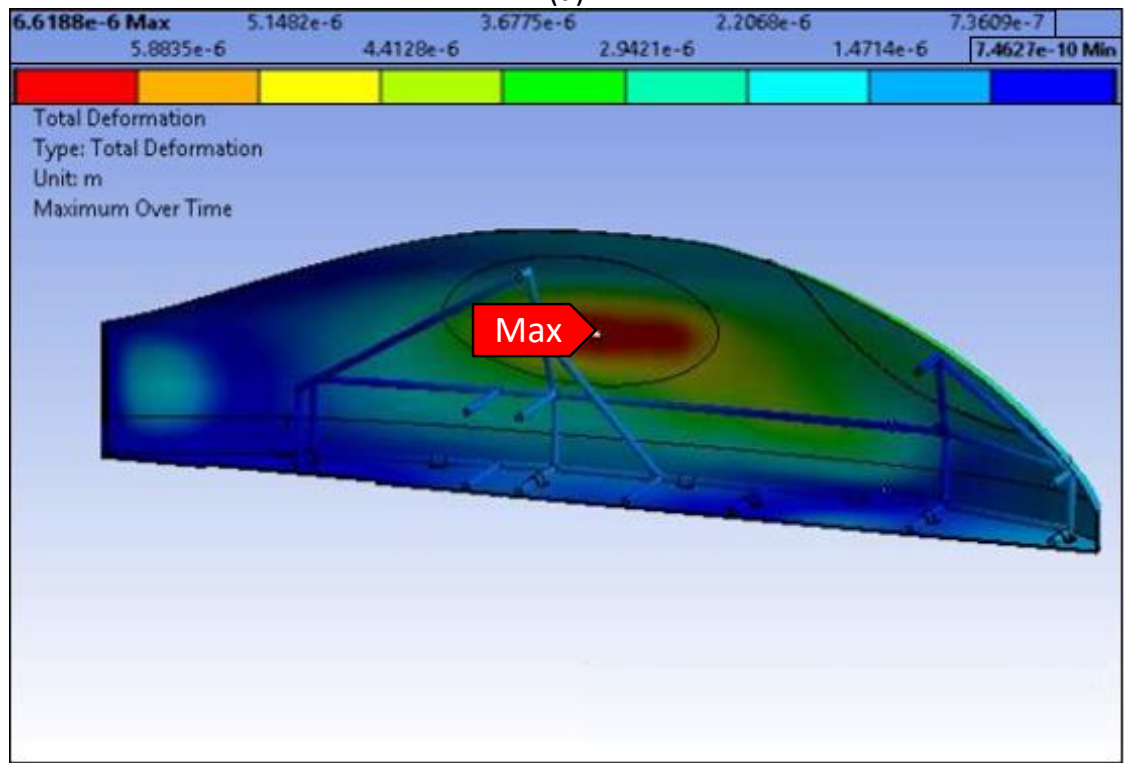

(b)

Fig. 14. Total deformation of prototype car at (a) overview, (b) view from symmetry plane

According to Figure 15(a), the maximum stress recorded is $32357 \mathrm{~Pa}$ which can be seen at the edge of the shell extruded hole around the chassis support as shown in Figure 15(b). Apart from the highly stressed region, the second highly stressed region occurs at the chassis junction intersection up to $30 \mathrm{kPa}$ as shown in Figure 15 (c). Irregularities or discontinuities, such as hole and intersection can cause a disruption to stress flow and stress concentrations in a localised region [38]. Other than the two parts which experience a relatively higher stress, most of the other regions experience stresses below $21576 \mathrm{~Pa}$. On the other hand, the stresses experienced by acrylic parts, i.e., the window and windscreen, are well below $17982 \mathrm{~Pa}$. 


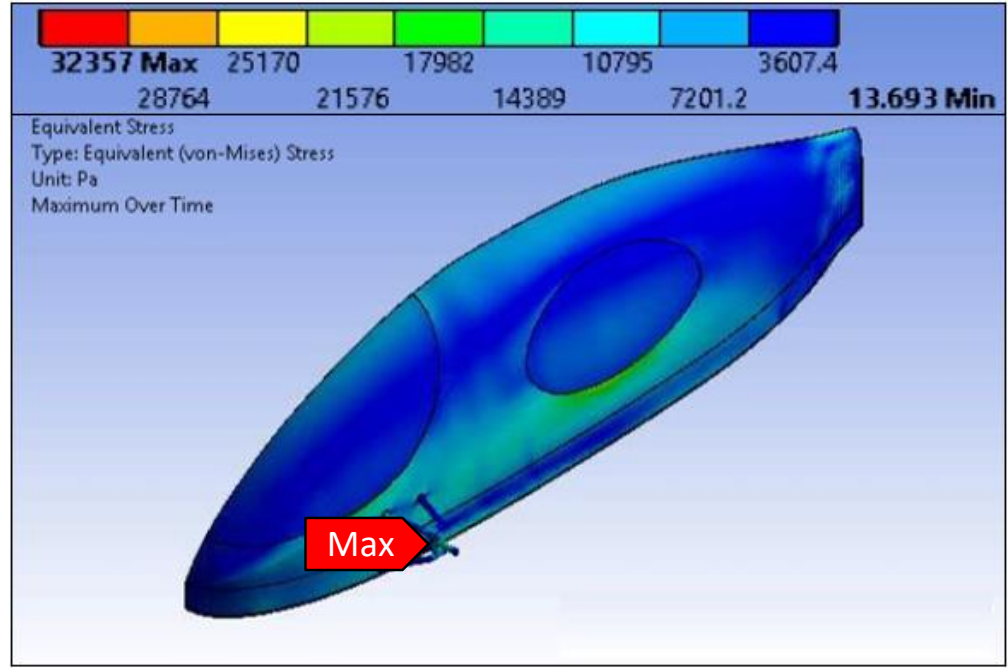

(a)

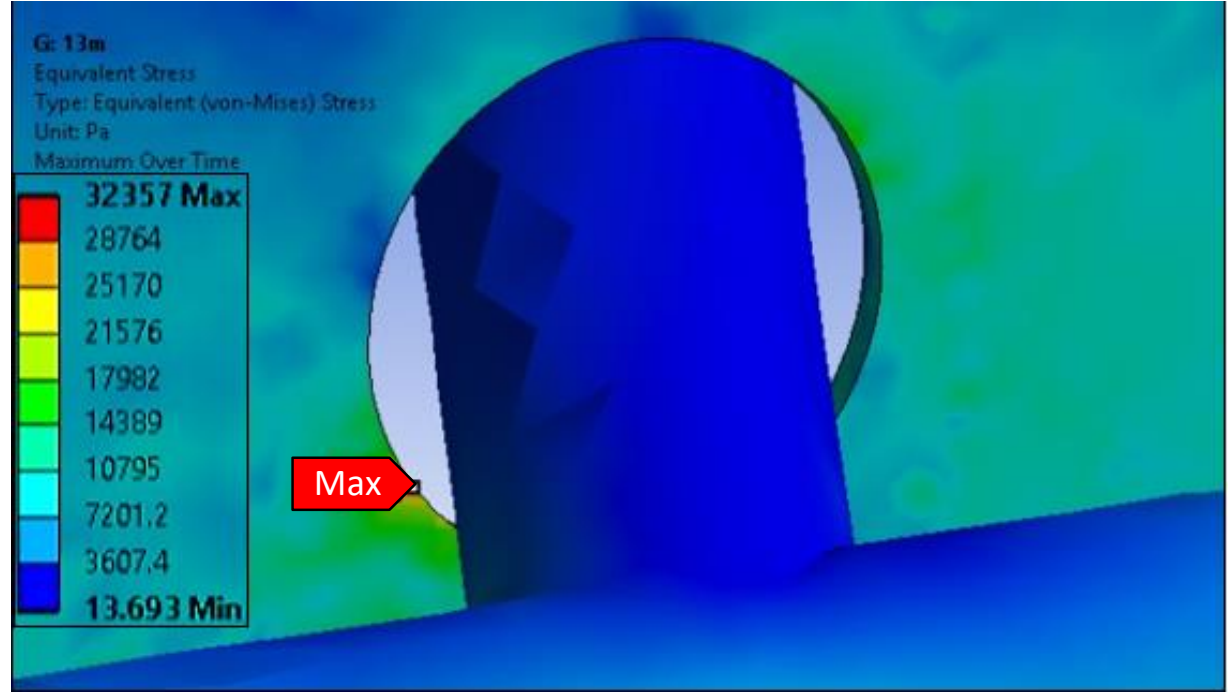

(b)

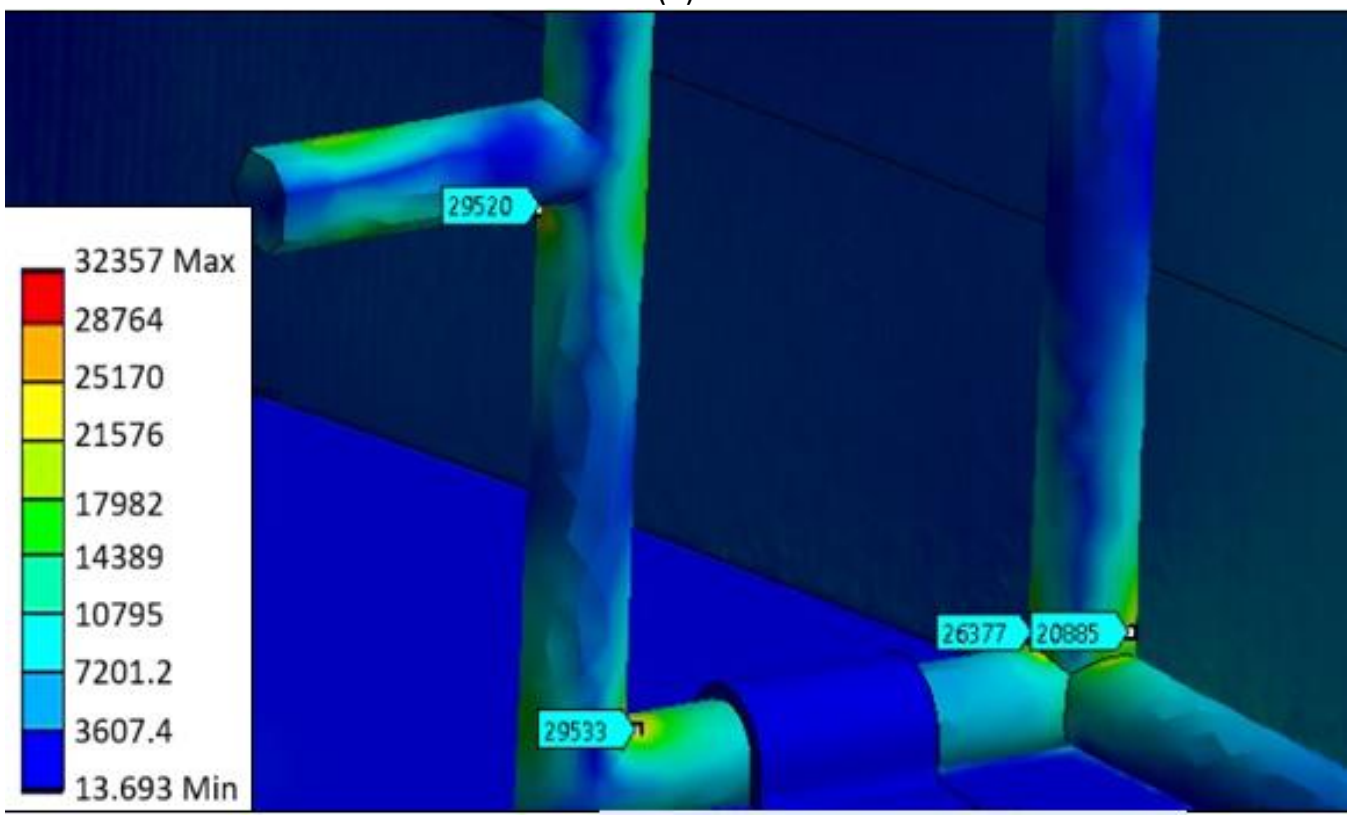

(c)

Fig. 15. Equivalent von-Mises stress of prototype car at (a) overview, (b) shell hole around chassis support, (c) chassis junction 
Based on Figure 16, the maximum equivalent elastic strain is $2.7619 \mathrm{e}-6 \mathrm{~m} / \mathrm{m}$ which is relatively small, and it occurs at the windscreen of the vehicle. The second highest equivalent elastic strain occurs at the centre surface of the window as shown in the Figure 16(a) with a magnitude around $2.1483 \mathrm{e}-6 \mathrm{~m} / \mathrm{m}$. As shown in Figure 13(b), the windscreen is subjected to high compressive loads at the nose area, and the loads decrease in strength downstream until there are tension loads at the aft of the windscreen. The window is also subjected to tension loads. Generally, acrylic material has a high compressive strength than tensile strength. Therefore, more elongation is captured at regions experiencing tension loads for acrylic parts.

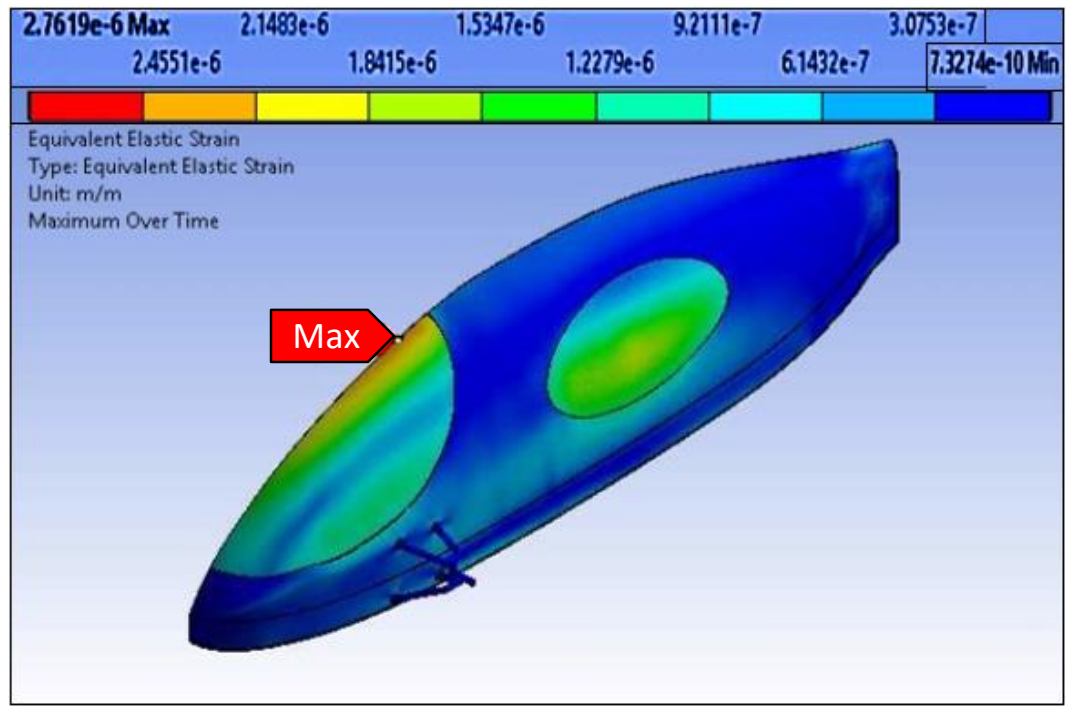

(a)

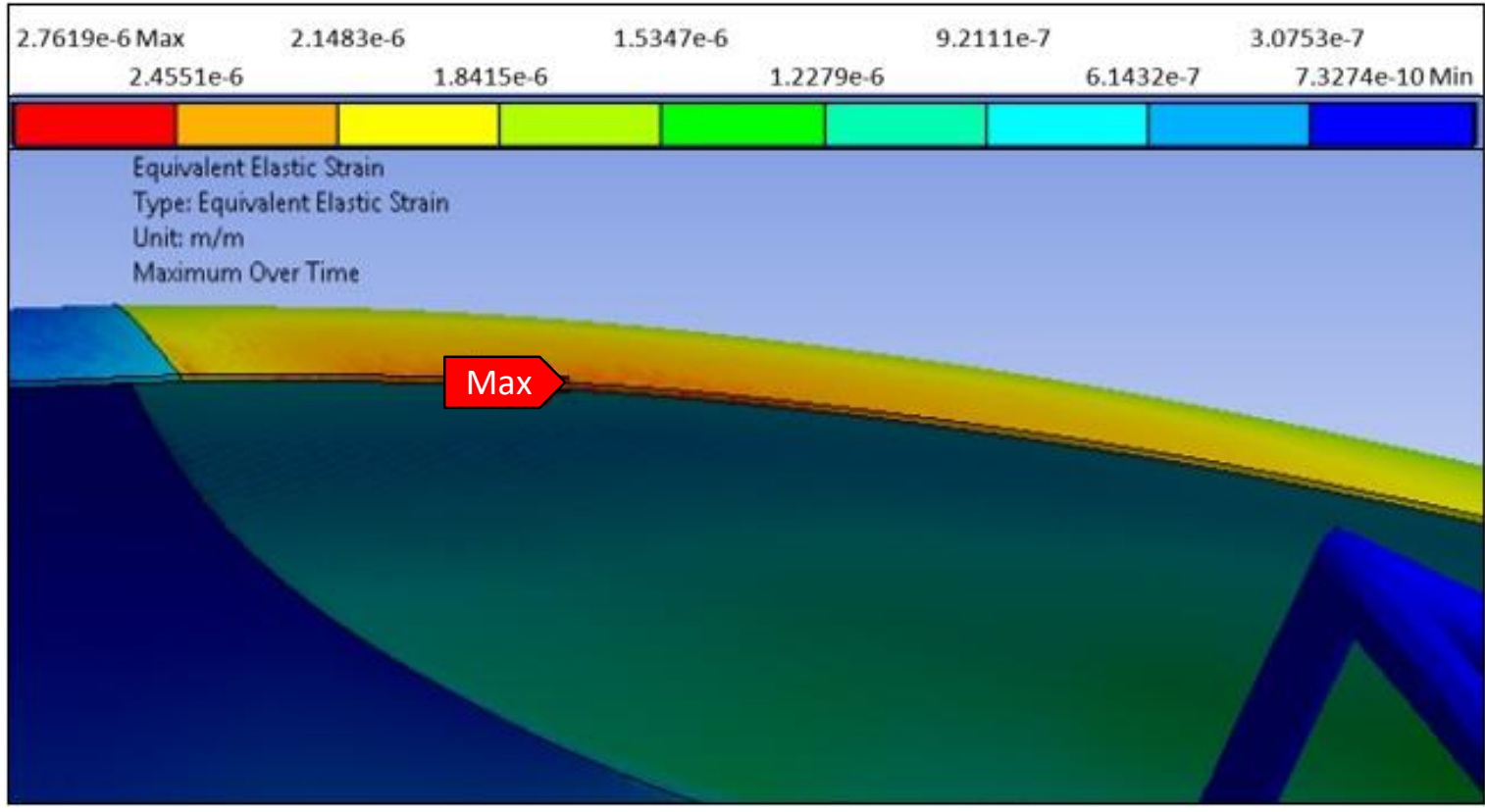

(b)

Fig. 16. Equivalent elastic strain of prototype car at (a) overview, (b) view from symmetry plane

\subsection{Car Safety Level Validation}

$A$ validation study on the car safety level was carried out by adopting theoretical analysis. In the process of generating structural results in the solver, the main mechanical properties used are the Young modulus (E) and Poisson ratio ( $v$ ) of each simulated structure [39]. Note that the stresses and 
strains are computed from the resulted displacements. Equivalent von Mises stress, $\sigma_{v M}$ is the stress used to assess whether a material experiences plastic deformation. The stresses experienced by the prototype car must be less than the yield strength, $S_{y}$ of the construction material for the vehicle to perform efficiently under normal driving conditions without compromising its structural integrity. An adequate safety factor, $\mathrm{N}=2.5$ was included in the design calculations to raise the safety margin above its intended load [4]. The safety factor for the design purpose is shown as follows.

$\sigma_{v M}<\frac{S_{y}}{N}$

Note that from the analysis, the maximum stress (32357 Pa) happens at the shell with the proposed flax composite materials, which has yield strength of $372.8 \mathrm{e} 6 \mathrm{~Pa}$. The term at the right side of the inequality of Eq. (14) for flax composite accounts for $149.12 \mathrm{e} 6 \mathrm{~Pa}$, which is still more than 4000 times higher than the maximum stress obtained from the analysis. Hence, it can be implied that the proposed material is safe for the vehicle to travel at the speed of $25 \mathrm{~km} / \mathrm{hr}$.

On equivalent plastic strain, it grows when the material is actively yielding. Note that the equivalent von Mises stress results are lower than the materials yield strength. This indicates that there is no equivalent plastic strain in the analysis with very small equivalent elastic strain. According to Dol [4], one of the conditions to ensure a safe design is that the maximum elastic deformation should be less or equal to $15 \mathrm{~mm}$. As the maximum equivalent elastic strains are $2.7619 \mathrm{e}-6 \mathrm{~m} / \mathrm{m}$ and $2.8173 \mathrm{e}-6 \mathrm{~m} / \mathrm{m}$ for proposed material sets, the design is declared safe for travelling at $25 \mathrm{~km} / \mathrm{hr}$.

\section{Conclusion}

This study is largely aimed at gaining better overview and understanding of the fluid-structure interaction of the fully assembled SEM prototype car travelling in low speed using several materials including the Flax fibre composite. From both the deformation and the von Mises stress analyses, it is concluded that the proposed material set is safe to be used in SEM car designs. Moreover, it is a sensible alternative material option for the SEM design travelling at low speeds since the proposed material is cheaper and more eco-friendly than the common materials.

\section{Acknowledgement}

The authors would like to convey their sincere gratitude to Dr. Aslina Anjang Ab Rahman, Senior Lecturer, Universiti Sains Malaysia for her kind and proper guidance in composite materials research. This research was partially supported by the Fundamental Research Grant No: PAERO/6071418, provided by the Ministry of Higher Education of Malaysia.

\section{References}

[1] Mayyas, Ahmad T., A. R. Mayyas, and M. Omar. "Sustainable lightweight vehicle design: a case study in Eco-Material selection for Body-In-White." In Lightweight Composite Structures in Transport, pp. 267-302. Woodhead Publishing, 2016. https://doi.org/10.1016/B978-1-78242-325-6.00011-6

[2] Acosta, Bryand. "Shell Eco-Marathon." Senior Design Project Final Report. Florida Internatonal Unversity (2012).

[3] Leong, lan Mun Choong. "Design and Fabrication of a Fuel Efficient Simple Vehicle Chassis." (2010).

[4] Dol, S. S. "Design and Development of a Prototype Vehicle for Shell Eco-Marathon." International Journal of Mechanical and Mechatronics Engineering 10, no. 3 (2016): 546-552. https://doi.org/10.5281/zenodo.1339177

[5] Omer, M. "Design and Analysis of Composite Chassis for Shell Eco Marathon Prototype Vehicle 2016 using Finite Element Analysis." Bachelor Thesis, Rwthaachen University (2016). 
[6] Tsirogiannis, Evangelos Ch, Gerasimos I. Siasos, Georgios E. Stavroulakis, and Sofoklis S. Makridis. "Lightweight Design and Welding Manufacturing of a Hydrogen Fuel Cell Powered Car's Chassis." Challenges 9, no. 1 (2018): 25. https://doi.org/10.3390/challe9010025

[7] Global, Shell. "SHELL ECO-MARATHON 2020 OFFICIAL RULES CHAPTER I." (2019).

[8] Yan, Libo, Nawawi Chouw, and Krishnan Jayaraman. "Flax fibre and its composites-A review." Composites Part B: Engineering 56 (2014): 296-317. https://doi.org/10.1016/i.compositesb.2013.08.014

[9] Yusoff, Mohd Zuhri Mohamed, and Mohamed Ibrahim J. Ibrahim. "Optimization of interlocking structures made of flax fibre composites to improve its energy absorption capability." Journal of Advanced Research in Applied Sciences and Engineering Technology 10, no. 1 (2018): 1-17.

[10] Ha, Sang Truong, Long Cu Ngo, Muhammad Saeed, Byoung Jin Jeon, and Hyounggwon Choi. "A comparative study between partitioned and monolithic methods for the problems with 3D fluid-structure interaction of blood vessels." Journal of Mechanical Science and Technology 31, no. 1 (2017): 281-287. https://doi.org/10.1007/s12206-016-1230-2

[11] Ansys Inc. "ANSYS Coupled-Field Analysis Guide." (2005).

[12] Andersson, Christoffer, and Daniel Ahl. "Fluid structure interaction: Evaluation of two coupling techniques." (2011).

[13] Torii, R., M. A. R. I. E. Oshima, T. O. S. H. I. O. Kobayashi, K. I. Y. O. S. H. I. Takagi, and TAYFUN E. Tezduyar. "Fluidstructure interaction modeling of blood flow and arterial-wall deformation: influence of structural modeling." submitted to Computational Mechanics (2007).

[14] Ismail, Farzad, Mohamad Shukri Zakaria, Masaaki Tamagawa, Ahmad Fazli Abdul Azi, Surjatin Wiriadidjaya, Adi Azrif Basri, and Kamarul Arifin Ahmad. "Computational fluid dynamics study of blood flow in aorta using OpenFOAM." Journal of Advanced Research in Fluid Mechanics and Thermal Sciences 43, no. 1 (2018): 81-89.

[15] Lombardi, Matteo, Massimiliano Cremonesi, Andrea Giampieri, Nicola Parolini, and Alfio Quarteroni. "A strongly coupled fluid-structure interaction model for wind-sail simulation." 4th High Performance Yacht Design (2012): 212-221.

[16] Hsu, M.-C. "Fluid-Structure Interaction Analysis of Wind Turbines." PhD diss., University of California, San Diego, 2012.

[17] Ali, Intizar, Abdul Hameed Memon, M. Tarique Bhatti, Dileep Kumar, Ishfaque Ali Qazi, and Sajjad Banghwar. "Dynamic Fluid-Structure Interaction Analysis of Propeller Aircraft Wing." American Scientific Research Journal for Engineering, Technology, and Sciences (ASRJETS) 45, no. 1 (2018): 64-74.

[18] Olsson, Simon, and Jari Kesti. "Fluid structure interaction analysis on the aerodynamic performance of underbody panels." Master's thesis, 2014.

[19] Patil, Sunil, Robert Lietz, Sudesh Woodiga, Hojun Ahn, Levon Larson, Ronald Gin, Michael Elmore, and Alexander Simpson. Fluid Structure Interaction Simulations Applied to Automotive Aerodynamics. No. 2015-01-1544. SAE Technical Paper, 2015.

https://doi.org/10.4271/2015-01-1544

[20] Knight, Jason, Simon Fels, George Haritos, and Thomas Carolus. Fluid-structure interaction of a spring-mounted symmetrical rigid wing for drag reduction of cars at higher wind velocities. No. 2020-01-5037. SAE Technical Paper, 2020.

https://doi.org/10.4271/2020-01-5037

[21] Al-Rawi, Mohammad, and Abderrahmane Oumssount. "One-Way Fluid Structure Interaction of a Go-Kart Spoiler Using CFD Analysis." In Multidisciplinary Digital Publishing Institute Proceedings, vol. 49, no. 1, p. 51.2020. https://doi.org/10.3390/proceedings2020049051

[22] Knight, J. J., A. D. Lucey, and C. T. Shaw. "Fluid-structure interaction of a two-dimensional membrane in a flow with a pressure gradient with application to convertible car roofs." Journal of wind engineering and industrial aerodynamics 98, no. 2 (2010): 65-72. https://doi.org/10.1016/j.jweia.2009.09.003

[23] Broniszewski, Jakub, and Janusz Piechna. "A fully coupled analysis of unsteady aerodynamics impact on vehicle dynamics during braking." Engineering Applications of Computational Fluid Mechanics 13, no. 1 (2019): 623-641. https://doi.org/10.1080/19942060.2019.1616326

[24] Tao, Li-li, Guang-sheng Du, Li-ping Liu, Yong-hui Liu, and Zhu-feng Shao. "Experimental study and finite element analysis of wind-induced vibration of modal car based on fluid-structure interaction." Journal of Hydrodynamics, Ser. B 25, no. 1 (2013): 118-124. https://doi.org/10.1016/S1001-6058(13)60345-5

[25] Ahamed, MdFayaz, Sharmin Atique, MdAbulKhair Munshi, and Tuomas Koiranen. "A concise description of one way and two way coupling methods for fluid-structure interaction problems." Imperial Journal of Interdisciplinary Research 3, no. 3 (2017). 
[26] Yue, Y. "Numerical Methods for Fluid-Structure Interaction: Analysis and Simulations." PhD diss., Brown University, 2014.

[27] Khuwaranyu, K., and S. Putivisutisak. "Combined low-Reynolds-number k model with length scale correction term for recirculating flows." Journal of Engineering and Technology Research 1, no. 8 (2009): 171-180. https://doi.org/10.5897/JETR.9000019

[28] Benra, Friedrich-Karl, Hans Josef Dohmen, Ji Pei, Sebastian Schuster, and Bo Wan. "A comparison of one-way and two-way coupling methods for numerical analysis of fluid-structure interactions." Journal of applied mathematics 2011 (2011). https://doi.org/10.1155/2011/853560

[29] Ahmed, Syed R., G. Ramm, and G. Faltin. "Some salient features of the time-averaged ground vehicle wake." SAE Transactions (1984): 473-503. https://doi.org/10.4271/840300

[30] Chizari, Hossain, and Farzad Ismail. "A grid-insensitive Ida method on triangular grids solving the system of euler equations." Journal of Scientific Computing 71, no. 2 (2017): 839-874. https://doi.org/10.1007/s10915-016-0323-5

[31] Ismail, Farzad, Pablo M. Carrica, Tao Xing, and Frederick Stern. "Evaluation of linear and nonlinear convection schemes on multidimensional non-orthogonal grids with applications to KVLCC2 tanker." International journal for numerical methods in fluids 64, no. 8 (2010): 850-886.

https://doi.org/10.1002/fld.2174

[32] Chizari, Hossain, and Farzad Ismail. "Accuracy variations in residual distribution and finite volume methods on triangular grids." Bulletin of the Malaysian Mathematical Sciences Society 40, no. 3 (2017): 1231-1264. https://doi.org/10.1007/s40840-015-0292-0

[33] Mohammed, Layth, MOHAMED NM Ansari, Grace Pua, Mohammad Jawaid, and M. Saiful Islam. "A review on natural fiber reinforced polymer composite and its applications." International Journal of Polymer Science 2015 (2015). https://doi.org/10.1155/2015/243947

[34] Clyne, T. W., and Derek Hull. An introduction to composite materials. Cambridge university press, 2019. https://doi.org/10.1017/9781139050586

[35] Sparnins, Edgars. "Mechanical properties of flax fibers and their composites." PhD diss., Luleå tekniska universitet, 2009.

[36] Wang, Zhi-Kui, Gwo-Chung Tsai, and Chen Yi-Bao. "One-way fluid-structure interaction simulation of an offshore wind turbine." International Journal of Engineering and Technology Innovation 4, no. 3 (2014): 127.

[37] Saghafi, Hamed. "Mechanical behavior of flat and curved laminates interleaved by electrospun nanofibers." PhD diss., alma, 2014.

[38] Loughborough University. "Stress Concentration." in Open Engineering Resources Pilot Project Materials, 2010 https://doi.org/10.1300/j015v03n03 28

[39] Gomes, Erica Alves, Hugo Henrique Diana, Juliana Santos Oliveira, Yara Teresinha Corrêa Silva-Sousa, Adriana Cláudia Lapria Faria, and Ricardo Faria Ribeiro. "Reliability of FEA on the results of mechanical properties of materials." Brazilian dental journal 26, no. 6 (2015): 667-670.

https://doi.org/10.1590/0103-6440201300639 